\title{
Renoprotection with SGLT2 inhibitors in type 2 diabetes over a spectrum of cardiovascular and renal risk
}

\author{
Francesco Giorgino ${ }^{1 *}\left(\mathbb{D}\right.$, Jiten Vora ${ }^{2}$, Peter Fenici ${ }^{3}$ and Anna Solini ${ }^{4}$
}

\begin{abstract}
Approximately half of all patients with type 2 diabetes (T2D) develop a certain degree of renal impairment. In many of them, chronic kidney disease (CKD) progresses over time, eventually leading to end-stage kidney disease (ESKD) requiring dialysis and conveying a substantially increased risk of cardiovascular morbidity and mortality. Even with widespread use of renin-angiotensin system blockers and tight glycemic control, a substantial residual risk of nephropathy progression remains. Recent cardiovascular outcomes trials investigating sodium-glucose cotransporter 2 (SGLT2) inhibitors have suggested that these therapies have renoprotective effects distinct from their glucoselowering action, including the potential to reduce the rates of ESKD and acute kidney injury. Although patients in most cardiovascular outcomes trials had higher prevalence of existing cardiovascular disease compared with those normally seen in clinical practice, the proportion of patients with renal impairment was similar to that observed in a real-world context. Patient cardiovascular risk profiles did not relevantly impact the renoprotective benefits observed in these studies. Benefits were observed in patients across a spectrum of renal risk, but were evident also in those without renal damage, suggesting a role for SGLT2 inhibition in the prevention of CKD in people with T2D. In addition, recent studies such as CREDENCE and DAPA-CKD offer a greater insight into the renoprotective effects of SGLT2 inhibitors in patients with moderate-to-severe CKD. This review outlines the evidence that SGLT2 inhibitors may prevent the development of CKD and prevent and delay the worsening of CKD in people with T2D at different levels of renal risk.
\end{abstract}

Keywords: Diabetes mellitus, Renal dysfunction, Renal protection, cardiovascular risk

\section{Introduction}

Renal disorders are common in type 2 diabetes (T2D), with approximately $50 \%$ of patients developing some degree of renal impairment and an increasing prevalence of both conditions over time [1]. An analysis of the US Diabetes Collaborative Registry revealed that $94 \%$ of people with T2D presented with at least one cardiovascular

\footnotetext{
*Correspondence: francesco.giorgino@uniba.it

${ }^{1}$ Department of Emergency and Organ Transplantation, Section of Internal Medicine, Endocrinology, Andrology and Metabolic Diseases, University of Bari Aldo Moro, Policlinico, Piazza Giulio Cesare, 11, 70124 Bari, Italy

Full list of author information is available at the end of the article
}

(CV), metabolic, or renal comorbidity, including $20 \%$ with chronic kidney disease (CKD) [2].

The risk of renal disorders in T2D includes the development of multiple phenotypes of organ damage, often overlapping and ultimately progressing, similar to what occurs for cardiovascular disease (CVD) (Fig. 1); many people with T2D already have some degree of renal dysfunction or abnormality at the time of diagnosis, and this may evolve over time, potentially leading to the development of CKD and ultimately to end-stage kidney disease (ESKD) [3, 4]. The UK Prospective Diabetes Study (UKPDS) showed annual accrual rates of approximately $2-3 \%$ for the development of microalbuminuria, transition of micro- to macroalbuminuria, and elevated plasma 
(See figure on next page.)

Fig. 1 The renal risk spectrum in T2D. a In addition to hyperglycemia, a range of other conditions can increase the risk of adverse renal events in T2D, such as AKI incidents, HU, and prolonged HK. $\mathbf{b}$ CKD amplifies the risk of adverse CV outcomes at any stage. In addition to developing along its own continuum, CKD acts as an amplifier of CV risk, as shown in the rear projection, which highlights that the presence of CKD of any stage increases a person's CV risk, and that the more advanced the CKD, the greater the increase in CV risk. In effect, this decreases the time taken to cross the CV event threshold (denoted by the leftward shift from A, B). AKl acute kidney injury, CAD coronary artery disease, CaReMe cardio-renal-metabolic, CKD chronic kidney disease, CV cardiovascular, ESKD end-stage kidney disease, HK hyperkalemia, HU hyperuricemia, T2D type 2 diabetes

creatinine or need for renal replacement therapy (RRT) [5]. Similarly, in large outcomes trials evaluating angiotensin receptor blockers in people with $\mathrm{T} 2 \mathrm{D}$, progression of nephropathy occurred in approximately $15-27 \%$ of placebo-treated patients over 2 years, depending on the level of baseline risk [6-8]. Furthermore, observational studies have identified duration of diabetes as an independent risk factor for progression of renal impairment $[9,10]$.

Even small decreases in estimated glomerular filtration rate (eGFR) are associated with an increased risk of CV events, including CV mortality [11, 12]. A large-scale analysis $(\mathrm{N}=1,120,295)$ in a cohort not undergoing RRT found that the adjusted hazard ratio (HR) for CV events increased from 1.4 in those with eGFR of $45-59 \mathrm{~mL} /$ $\min / 1.73 \mathrm{~m}^{2}$ to 3.4 in those with eGFR of $<15 \mathrm{~mL} /$ $\mathrm{min} / 1.73 \mathrm{~m}^{2}$. Indeed, up to half of deaths in patients with ESKD are thought to be due to CV complications [13]. Therefore, progressive renal impairment increases the risk of patients experiencing not only renal but also $\mathrm{CV}$ morbidity and mortality.

Studies of either intensive glucose-lowering therapy [14-18] or specific glucose-lowering drugs versus standard of care [19-24] have consistently shown that correction of hyperglycemia reduces microvascular complications, including nephropathy, in people with T2D. However, the effects of intensive glucose lowering are more evident in terms of reducing albuminuria, as compared with harder renal endpoints such as ESKD, renal death, or fall in eGFR [18]. Moreover, people with T2D may remain at significant risk of progression of CKD despite strict control of both hyperglycemia and hypertension, and the use of therapies such as renin-angiotensin system (RAS) blockers [25].

Sodium-glucose cotransporter 2 (SGLT2) is predominantly expressed in the proximal convoluted renal tubule, and is responsible for approximately $90 \%$ of glucose reabsorption by the kidney. Hence, inhibition of this system facilitates the excretion of glucose and sodium in the urine, thereby reducing elevated blood glucose levels, triggering osmotic diuresis, and favoring body weight and blood pressure reductions [25-28]. SGLT2 inhibitors have shown clear $\mathrm{CV}$ and renal benefits in people with T2D [22-24, 29-31]. The renoprotective effects of
SGLT2 inhibitors across the spectrum of both CV and renal risk are reviewed here.

\section{Renal benefits of SGLT2 inhibitors in people with T2D}

The renoprotective effects of SGLT2 inhibitors in people with T2D have been evaluated in five major $\mathrm{CV}$ outcomes trials (CVOTs): EMPA-REG OUTCOME (empagliflozin) [24], CANVAS program, which comprised two randomized, double-blind, placebo-controlled phase 3 trials: CANVAS and CANVAS-R (canagliflozin) [22], DECLARE-TIMI 58 (dapagliflozin) [23], and VERTIS CV (ertugliflozin) [32]. Each of these trials assessed composites of renal events, including 'hard' endpoints such as ESKD or renal death, as outcome measures, usually as secondary endpoints. In addition, numerous studies in patients at different levels of renal risk have used measurements such as urinary albumin:creatinine ratio (UACR), eGFR, and serum uric acid levels as overall renal risk markers. Together, these $\mathrm{CV}$ outcomes studies indicated that SGLT2 inhibitors could prevent the development of CKD and prevent or delay the worsening of CKD in people with T2D at any level of renal risk. The CREDENCE trial in people with CKD and T2D [33] and DAPA-CKD trial in people with CKD with and without T2D [34] were designed to investigate renal outcomes and demonstrated that SGLT2 inhibitors can reduce the risk of worsening CKD.

\section{Major outcomes trials with SGLT2 inhibitors in people with T2D at varying levels of $C V$ and renal risk EMPA-REG OUTCOME, CANVAS program, and VERTIS CV}

EMPA-REG OUTCOME was a randomized, doubleblind, placebo-controlled phase 3 trial, involving 7020 people with T2D, almost all with established CVD [24]. The mean eGFR at baseline was $74.1 \mathrm{~mL} / \mathrm{min} / 1.73 \mathrm{~m}^{2}$ and the median UACR was $18 \mathrm{mg} / \mathrm{g}$ (Table 1). Prespecified renal outcomes in this study included incident or worsening nephropathy (defined as progression to macroalbuminuria, doubling of serum creatinine associated with eGFR $<45 \mathrm{~mL} / \mathrm{min} / 1.73 \mathrm{~m}^{2}$, initiation of RRT, or death from renal causes) and incident albuminuria [30]. Fewer patients in the empagliflozin group than in the placebo group experienced incident or worsening 


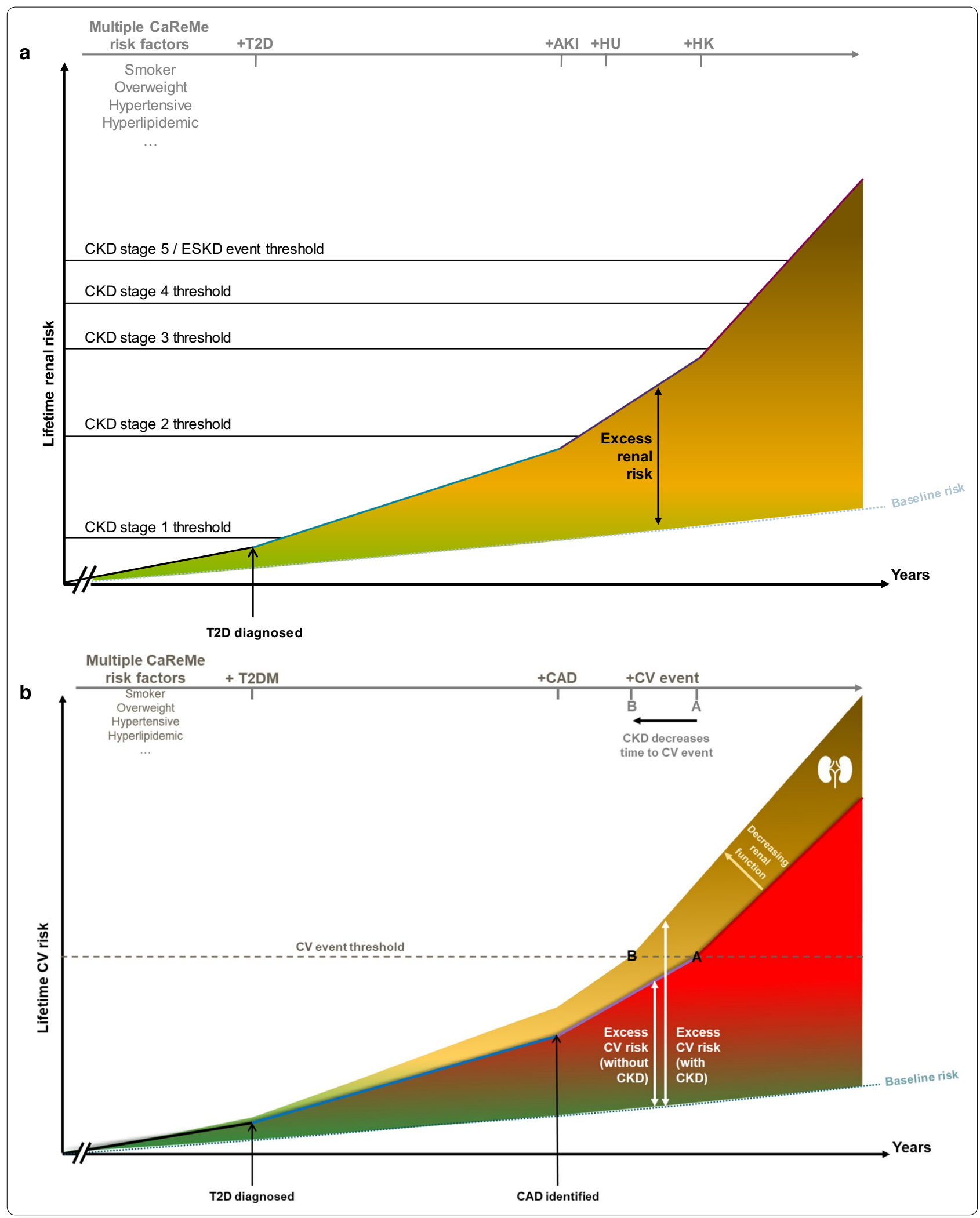




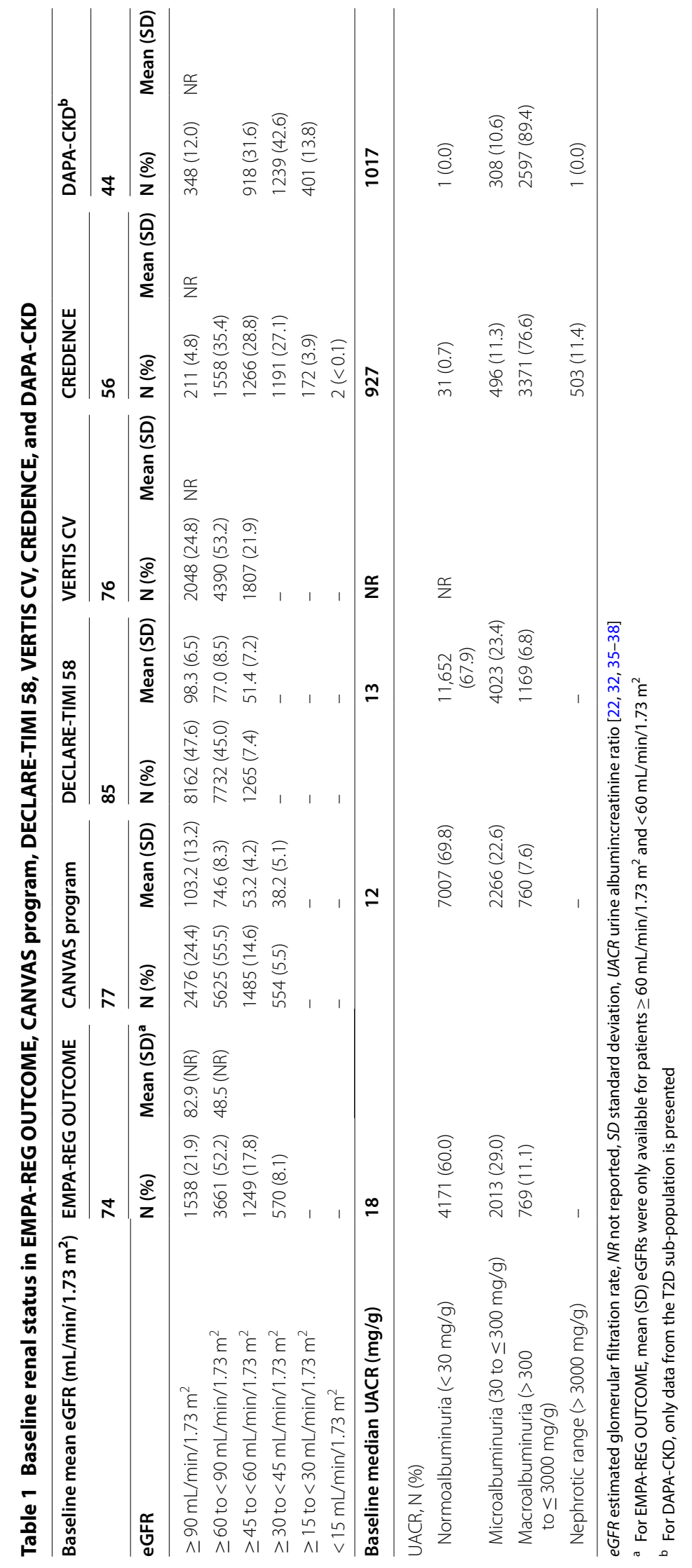


nephropathy (HR: 0.61; 95\% confidence interval [CI]: $0.53,0.70)$. A main driver for the reduction in nephropathy with empagliflozin was a slower progression to macroalbuminuria (HR: 0.62; 95\% CI 0.54, 0.72). Compared with placebo, empagliflozin was also associated with significant improvements in a post-hoc composite endpoint of incident or worsening nephropathy or CV death (HR: $0.61 ; 95 \%$ CI $0.55,0.69$ ), progression to macroalbuminuria (HR: 0.62 ; 95\% CI 0.54, 0.72), and initiation of RRT (HR: 0.45; 95\% CI 0.21, 0.97), with no differences reported between the two therapeutic doses [30].

Similar results were observed with canagliflozin in CANVAS and CANVAS-R [22]. These studies included 10,142 people with T2D at various levels of CV risk, a mean baseline eGFR of $76.5 \mathrm{~mL} / \mathrm{min} / 1.73 \mathrm{~m}^{2}$, and a median UACR of $12 \mathrm{mg} / \mathrm{g}$ (Table 1). A secondary renal outcome in CANVAS was progression of albuminuria ( $\geq 30 \%$ increase in albuminuria or change from either normoalbuminuria to microalbuminuria or from microalbuminuria to macroalbuminuria); there was also a prespecified exploratory composite renal outcome (40\% decrease in eGFR sustained for $\geq 2$ consecutive measurements, need for RRT, or death from renal causes). Progression of albuminuria occurred less frequently with canagliflozin compared with placebo (HR: 0.73; 95\% CI $0.67,0.79$ ), and regression of albuminuria was more frequent (HR: 1.70; 95\% CI 1.51, 1.91). The composite renal outcome was also reduced in canagliflozin-treated patients compared with placebo (HR: 0.60; 95\% CI 0.47, 0.77) [22].

Unlike EMPA-REG OUTCOME and the CANVAS program, the recent VERTIS CV study investigating ertugliflozin in 8246 people with T2D and established CVD did not show a statistically significant reduction in the secondary composite renal outcome (death from renal causes, RRT, or doubling of serum creatinine levels) in the ertugliflozin group compared with placebo (HR: 0.81; $95 \%$ CI 0.63, 1.04) [32]. Mean baseline eGFR of the VERTIS CV population was similar to those of EMPAREG OUTCOME and the CANVAS program (Table 1); however, owing to differences in outcome definition, renal efficacy outcomes should be compared with caution between trials, and further post-hoc analyses of the VERTIS CV data would be useful to provide a more direct comparison [32].

\section{DECLARE-TIMI 58}

DECLARE-TIMI 58 was a randomized, double-blind, placebo-controlled trial with dapagliflozin, involving people with T2D and either atherosclerotic CVD $(n=6971)$ or multiple CV risk factors $(n=10,189)$ [23]. Patients had relatively good renal function, with a mean eGFR at baseline of $85.2 \mathrm{~mL} / \mathrm{min} / 1.73 \mathrm{~m}^{2}$ and a median UACR of $13 \mathrm{mg} / \mathrm{g}$ (Table 1). Compared with placebo, dapagliflozin was associated with significant decreases in both the renal composite endpoint (sustained $\geq 40 \%$ decrease in eGFR to $<60 \mathrm{~mL} / \mathrm{min} / 1.73 \mathrm{~m}^{2}$, new ESKD, or renal or CV death, HR: 0.76 ; $95 \%$ CI $0.67,0.87$ ) and the additional composite that excluded CV death (HR: 0.53; 95\% CI 0.43, 0.66) [23]. Dapagliflozin also decreased the likelihood of new-onset macroalbuminuria (HR: 0.54; 95\% CI 0.45, 0.65), new-onset albuminuria (HR: 0.79; 95\% CI $0.72,0.87$ ), and albuminuria category deterioration (HR: $0.73 ; 95 \%$ CI $0.67,0.79)[39]$.

\section{CREDENCE}

The phase 3 CREDENCE trial was the first dedicated renal outcomes trial with an SGLT2 inhibitor, and involved 4401 people with CKD and T2D who were also receiving standard care with RAS inhibitors [33, 40]. The trial recruited people with overt albuminuria (almost $90 \%$ had UACR $>300 \mathrm{mg} / \mathrm{g}$ to $5000 \mathrm{mg} / \mathrm{g}$ ), and $59.8 \%$ of patients had an eGFR of $<60 \mathrm{~mL} / \mathrm{min} / 1.73 \mathrm{~m}^{2}$. The baseline renal measures for the trial showed that patients were highly albuminuric (median UACR of $927 \mathrm{mg} / \mathrm{g} / 24 \mathrm{~h}$ ) with a moderately reduced eGFR (mean eGFR of $56 \mathrm{~mL} / \mathrm{min} / 1.73 \mathrm{~m}^{2}$ ) (Table 1, Fig. 2). The relative risk of the primary renal composite endpoint (ESKD, doubling of serum creatinine, or renal or CV death) was $30 \%$ lower in the canagliflozin group than in the placebo group (HR: 0.70; 95\% CI 0.59, 0.82) [33, 41]. In canagliflozin-treated patients, the relative risks of the composite endpoint without CV death (HR: 0.66; 95\% CI 0.53, 0.81) and ESKD (HR: 0.68; 95\% CI 0.54, 0.86) were also lower compared with placebo [33].

\section{DAPA-CKD}

DAPA-CKD was the first phase 3 trial to investigate the safety and renal outcomes of an SGLT2 inhibitor in people with CKD, both with and without T2D [34]. It recruited 4304 people with CKD, of whom 2906 had comorbid T2D. All patients received standard care with RAS inhibitors and had reduced renal function, with a mean baseline eGFR of $43.1 \mathrm{~mL} / \mathrm{min} / 1.73 \mathrm{~m}^{2}(43.8 \mathrm{~mL} /$ $\min / 1.73 \mathrm{~m}^{2}$ in the T2D subpopulation); $48.3 \%$ of patients had a UACR of $>1000 \mathrm{mg} / \mathrm{g}$ (median UACR in the T2D subpopulation was $1016.2 \mathrm{mg} / \mathrm{g}$, Table 1). Similar significant reductions in the primary renal composite endpoint (eGFR $<50 \%$, ESKD, or renal or CV death) were observed for patients treated with dapagliflozin compared with placebo, both in those with T2D (HR: 0.64; 95\% CI 0.52, 0.79) and those without T2D (HR: 0.50; 95\% CI 0.35, 0.72). A significant reduction in the relative risk of the composite endpoint without CV death (HR: 0.56; 95\% CI 0.45, 0.68) and all-cause mortality (HR: 0.69; 95\% 


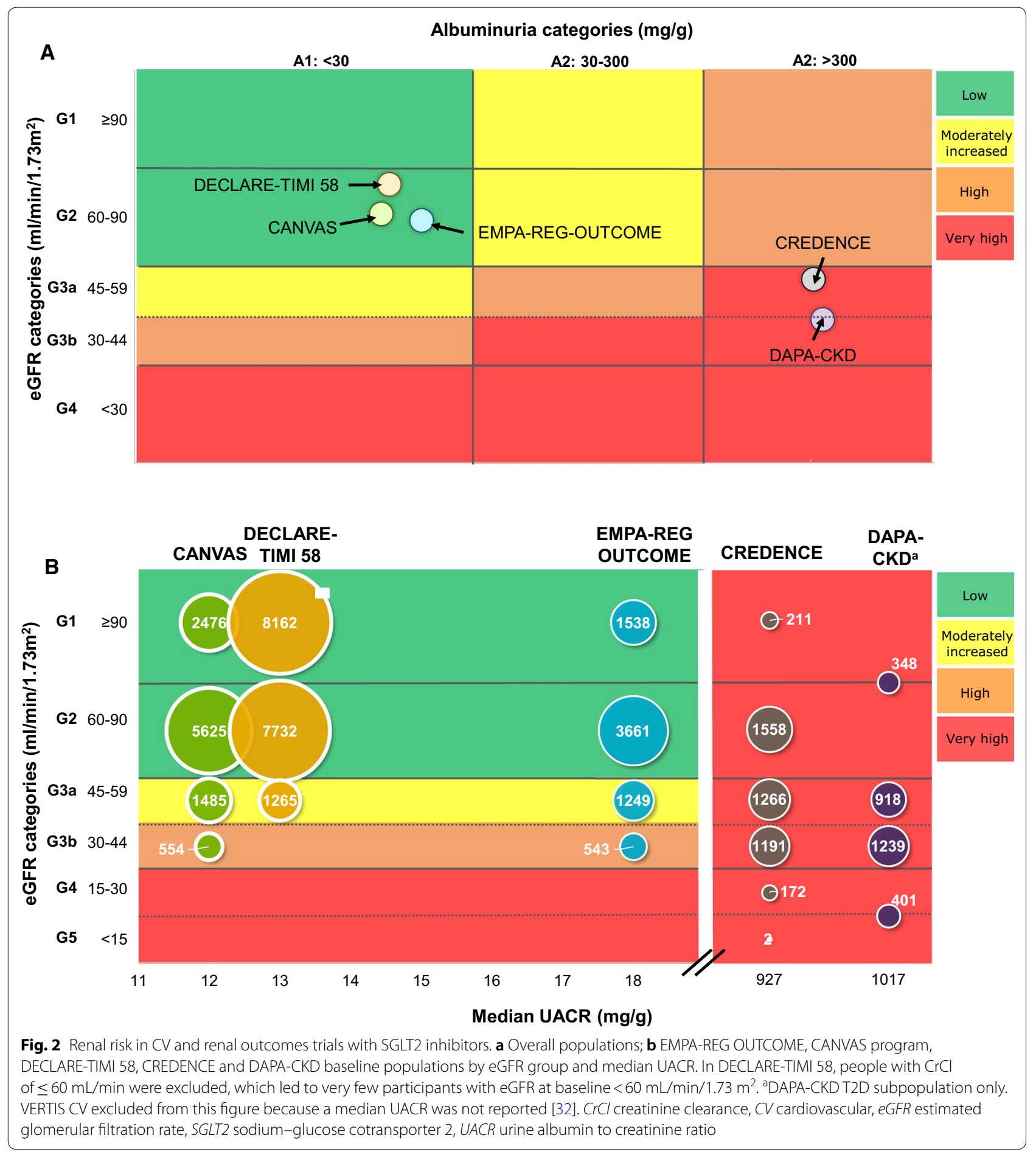

CI $0.53,0.88$ ) was also reported in the dapagliflozin arm compared with the placebo arm $[34,38]$.

\section{Meta-analyses of trials with SGLT2 inhibitors}

Two independent meta-analyses of the EMPA-REG OUTCOME, CANVAS program, DECLARE-TIMI 58, and CREDENCE trials found that SGLT2 inhibitors significantly reduced the risk of a renal composite including worsening renal function, ESKD, or death from renal causes compared with placebo (relative risk [RR]: 0.67; 95\% CI 0.52, 0.86 [42] and RR: 0.63; 95\% CI 0.56, 0.71 ; number needed to treat $[\mathrm{NNT}]=67)$ [43]. These 
outcomes were consistent with results from an earlier meta-analysis, which did not include CREDENCE [44].

These findings were also consistent with those of a meta-analysis of 27 studies involving 7363 patients treated with SGLT2 inhibitors (empagliflozin, dapagliflozin, canagliflozin, and ertugliflozin) [45], which revealed a significantly reduced risk of doubling of serum creatinine (or $40 \%$ decline in eGFR, in the case of DECLARETIMI 58), ESKD, or renal death (HR: 0.71; 95\% CI 0.53, 0.95). In addition, SGLT2 inhibitors significantly reduced the annual decline in eGFR slope, with a mean treatment difference of $1.35 \mathrm{~mL} / \mathrm{min} / 1.73 \mathrm{~m}^{2} /$ year [45]. An additional meta-analysis of 51 randomized controlled trials including a total of 24,163 people with T2D observed no significant differences between treatment with highand low-dose SGLT2 inhibitors in terms of renal-related adverse events, although composite renal outcomes were not investigated [46].

\section{Renoprotective effects of SGLT2 inhibitors according to baseline risk}

Renal benefits according to baseline CV risk

One meta-analysis of EMPA-REG OUTCOME, CANVAS program, and DECLARE-TIMI 58 showed that the renal benefit was observed both in patients with (HR: 0.56; 95\% CI 0.47, 0.67) and without (HR: 0.54; 95\% CI $0.42,0.71$ ) established atherosclerotic CVD, with no significant difference in effect between the two cohorts $(P=0.71$ for interaction) [44].

Similarly, post-hoc analyses from the CANVAS program and DECLARE-TIMI 58 reported similar decreases in composite renal risk in patients with (canagliflozin: HR: 0.67; 95\% CI 0.3, 1.51; dapagliflozin: HR: 0.58; 95\% CI 0.36, 0.92) and without (canagliflozin: HR: 0.52; 95\% CI 0.31, 0.72; dapagliflozin: HR: 0.52; 95\% CI 0.41, 0.66) heart failure at baseline $(P=0.93$ and $P=0.78$ for interaction, respectively) $[36,47]$. Studies investigating SGLT2 inhibitors in patients with heart failure with reduced ejection fraction (with and without T2D) have also recently reported numerical and substantial reductions in renal composite outcomes compared with placebo [dapagliflozin: HR: 0.71; 95\% CI 0.44, 1.16 (eGFR<50\%, ESKD, or renal death) [48]; empagliflozin: HR: 0.50; $95 \%$ CI $0.32,0.77$ (eGFR $<50 \%$ or ESKD)] [49]. A subanalysis of the DECLARE-TIMI 58 trial found a slightly greater reduction in the rate of a composite of $40 \%$ decline in eGFR, ESKD, or renal or CV death in patients without (HR: 0.75 ; 95\% CI 0.64, 0.89) compared with those with (HR: 0.80; 95\% CI 0.63, 1.01) prior myocardial infarction, however, the difference was not statistically significant $(P=0.69$ for interaction) [50].
Subgroup analyses from EMPA-REG OUTCOME and DECLARE-TIMI 58 reported similar renal outcomes irrespective of body mass index (BMI) category with empagliflozin and dapagliflozin therapy for people with T2D [30, 36]. The same observation was reported for the CREDENCE study of canagliflozin therapy for patients with diabetic nephropathy $\left(\mathrm{BMI}<30 \mathrm{~kg} / \mathrm{m}^{2}\right.$ : HR: 0.71 ; $95 \%$ CI 0.56, 0.80; BMI $\geq 30 \mathrm{~kg} / \mathrm{m}^{2}$ : HR: 0.68; 95\% CI 0.54, $0.86)$ [33].

\section{Renal benefits according to baseline renal risk}

Patients in the major outcomes trials differed in terms of their baseline renal risk as measured by eGFR and UACR (Table 1, Fig. 2). When compared, event rates for the renal composite endpoint were highest in the placebo arm of CREDENCE (40.4 per 1000 patient-years) and there were slightly more events in the placebo arms of VERTIS CV (12 per 1000 patient-years), the CANVAS program (9.0 per 1000 patient-years), and EMPA-REG OUTCOME (11.5 per 1000 patient-years) compared with DECLARE-TIMI 58 (7.0 per 1000 patient-years; Table 2).

Glycemic control resulting from SGLT2 inhibition relies on normal renal function, and hence decreased renoprotection might be anticipated in patients with renal impairment. However, there is evidence that SGLT2 inhibitors actually retain their renoprotection in people with T2D with impaired kidney function. Post-hoc analysis of the EMPA-REG OUTCOME trial reported no significant heterogeneity in the treatment effect of empagliflozin on a renal composite endpoint (serum creatinine doubling, RRT, or renal death) among patients according to baseline eGFR ( $P$ for interaction $=0.51$ ) [30]. However, compared with placebo, empagliflozin reduced the rate of acute renal failure and acute kidney injury (AKI) by $3.1 \%$ and $1.5 \%$, respectively, in patients with baseline eGFR $<60 \mathrm{~mL} / \mathrm{min} / 1.73 \mathrm{~m}^{2}$ and $0.7 \%$ and $0.4 \%$, respectively, in those with normal renal function [30]. Although no significant interaction according to baseline UACR was identified for the impact of empagliflozin on the renal composite endpoint $(P$ for interaction $=0.18)[30]$, a post-hoc analysis reported that, compared with placebo, empagliflozin therapy attenuated eGFR decline to a greater extent in patients who had macroalbuminuria at baseline than in those with normoalbuminuria or microalbuminuria [52].

A post-hoc subgroup analysis of the CANVAS program reported that the impact of canagliflozin versus placebo on the composite renal outcome was larger in patients with macroalbuminuria (HR: 0.48; 95\% CI 0.31, 0.74 ) and normoalbuminuria (HR: 0.50 ; 95\% CI 0.33, 0.77 ) compared with those with microalbuminuria (HR: 0.98; 95\% CI 0.60, 1.60; $P$ for heterogeneity $=0.03$ ) [53]. Similarly, although canagliflozin attenuated eGFR decline 
Table 2 Renal composite event rates in EMPA-REG OUTCOME [35], CANVAS program [51], DECLARE-TIMI 58 [36], VERTIS CV [32], CREDENCE [33], and DAPA-CKD [34]

\begin{tabular}{|c|c|c|c|c|c|c|c|c|}
\hline & \multirow{2}{*}{$\begin{array}{l}\text { Treatment } \\
\text { arm }\end{array}$} & \multicolumn{5}{|c|}{ Cardiovascular outcomes trials } & \multicolumn{2}{|c|}{ Renal outcomes trial } \\
\hline & & $\begin{array}{l}\text { EMPA-REG } \\
\text { OUTCOME }\end{array}$ & $\begin{array}{l}\text { CANVAS } \\
\text { program }\end{array}$ & $\begin{array}{l}\text { DECLARE- } \\
\text { TIMI } 58\end{array}$ & $\begin{array}{l}\text { Meta-analysis } \\
\text { (fixed-effects } \\
\text { model) }^{\mathrm{a}}\end{array}$ & VERTIS CV & CREDENCE & DAPA-CKD \\
\hline \multirow{2}{*}{$\begin{array}{l}\text { Renal com- } \\
\text { posite (Event } \\
\text { rate per } 1000 \\
\text { patient- } \\
\text { years) }\end{array}$} & Placebo & 11.5 & 9.0 & 7.0 & \multirow{2}{*}{$\begin{array}{r}\text { Events }(\mathrm{n} / \mathrm{N}): \\
766 / 34,322\end{array}$} & 12 & 40.4 & NR \\
\hline & \multirow[t]{3}{*}{ SGLT2i } & 6.3 & 5.5 & 3.7 & & 9 & 27.0 & NR \\
\hline $\begin{array}{c}\text { Hazard ratio } \\
(95 \% \mathrm{Cl})\end{array}$ & & $0.54(0.40,0.75)$ & $\begin{array}{c}0.60(0.47 \\
0.77)\end{array}$ & $\begin{array}{c}0.53(0.43 \\
0.66)\end{array}$ & $0.55(0.48,0.64)$ & $\begin{array}{l}0.81(0.63 \\
1.04)\end{array}$ & $0.660 .53,0.81)$ & $0.64(0.52,0.79$ \\
\hline $\begin{array}{l}\text { Renal compos- } \\
\text { ite (3-year } \\
\text { NNT) }\end{array}$ & & 66 & 97 & 103 & - & - & 28 & NR \\
\hline
\end{tabular}

compared with placebo across all baseline levels of albuminuria, the treatment impact was greatest in patients with macroalbuminuria at baseline [53]. The authors suggested that canagliflozin could be particularly efficacious in patients with kidney disease driven by hyperfiltration or changes in vascular function, both of which lead to macroalbuminuria, although the lack of efficacy in patients with microalbuminuria was suggested to be a chance finding [53]. No significant interactions were confirmed, however, treatment with canagliflozin also led to the greatest numerical decrease in the rate of the renal-specific composite outcomes versus placebo in CREDENCE patients with baseline eGFR 45 to $<60 \mathrm{~mL} /$ $\mathrm{min} / 1.73 \mathrm{~m}^{2}$ (HR: $0.47 ; 95 \%$ CI $0.31,0.72$ ) compared with those with a baseline eGFR 30 to $<45 \mathrm{~mL} / \mathrm{min} / 1.73 \mathrm{~m}^{2}$ (HR: $0.71 ; 95 \%$ CI $0.53,0.94$ ) and 60 to $<90 \mathrm{~mL} / \mathrm{min} / 1.73$ $\mathrm{m}^{2}$ (HR: 0.81; 95\% CI 0.52, 1.26; $P$ for interaction $=0.18$ ), and in those with baseline UACR $>1000 \mathrm{mg} / \mathrm{g}$ (HR: $0.61 ; 95 \%$ CI $0.49,0.76)$ compared with those with $\mathrm{UACR} \leq 1000 \mathrm{mg} / \mathrm{g}$ (HR: 0.90; 95\% CI 0.54, 1.50, $P$ for interaction $=0.16)[33,54]$. The largest absolute risk reductions were also seen in patients with the lowest baseline eGFR subgroups $(P$ heterogeneity $=0.03)[54]$.

In a population with relatively less renal impairment, DECLARE-TIMI 58 did not report a significant difference in the efficacy of dapagliflozin as measured by the renal composite outcome based on patient baseline eGFR or UACR, although there were some numeric differences suggesting that the renoprotective effects of dapagliflozin may be slightly larger in patients with normal renal function (eGFR $\geq 90 \mathrm{~mL} / \mathrm{min} / 1.73 \mathrm{~m}^{2}$ : HR: 0.50 ; 95\% CI 0.34, 0.73; and eGFR 60 to $<90 \mathrm{~mL} / \mathrm{min} / 1.73 \mathrm{~m}^{2}$ : HR: 0.54; 95\% CI 0.40, 0.73; eGFR $<60 \mathrm{~mL} / \mathrm{min} / 1.73 \mathrm{~m}^{2}$ :
HR: 0.60 ; $95 \%$ CI $0.35,1.02)$ and those with macroalbuminuria (UACR> $300 \mathrm{mg} / \mathrm{g}$ : HR: $0.38 ; 95 \%$ CI 0.25 , 0.58; UACR < $30 \mathrm{mg} / \mathrm{g}:$ HR: $0.52 ; 95 \%$ CI 0.37, 0.74; and UACR $30-300 \mathrm{mg} / \mathrm{g}$ : HR: 0.59; 95\% CI 0.39, 0.87) [36]. Approximately $13.1 \%$ of DECLARE-TIMI 58 participants had CKD (defined as eGFR $<60 \mathrm{~mL} / \mathrm{min} / 1.73 \mathrm{~m}^{2}$, UACR $>300 \mathrm{mg} / \mathrm{g}$, or both) at baseline [36]. In these patients, dapagliflozin treatment was associated with a significantly lower rate of ESKD or renal death, compared with placebo (HR: 0.41; 95\% CI 0.20, 0.82), which was mostly driven by a lower rate of ESKD (HR: $0.31 ; 95 \%$ CI $0.13,0.79)$ [36].

In a meta-analysis of these trials, the renoprotective effects of SGLT2 inhibitors were consistent across all levels of baseline eGFR, although the greatest benefits were observed in patients with preserved renal function at baseline: the incidence of the renal composite was reduced by $63 \%$ in patients with a baseline eGFR $\geq 90 \mathrm{~mL} /$ $\min / 1.73 \mathrm{~m}^{2}$, by $40 \%$ in those with eGFR $60-90 \mathrm{~mL} /$ $\min / 1.73 \mathrm{~m}^{2}$, by $45 \%$ in those with eGFR $45-60 \mathrm{~mL} /$ $\mathrm{min} / 1.73 \mathrm{~m}^{2}$, and by $30 \%$ in those with eGFR $<45 \mathrm{~mL} /$ $\min / 1.73 \mathrm{~m}^{2}$ [42]. However, it should be noted that the majority of patients with high eGFR were recruited into the DECLARE-TIMI 58 trial and the majority of patients with low eGFR were recruited into CREDENCE (Table 1, Fig. 2), therefore the possibility of variation between different agents and/or study design cannot be dismissed. Treatment benefit was consistent irrespective of baseline albuminuria $(P$ trend $=0.66)$ and of RAS blockade $(P$ heterogeneity $=0.31)[42]$. No specific subgroup analysis has been reported to date, however, the DAPA-CKD trial of dapagliflozin included patients with eGFR 25 to $<30 \mathrm{~mL} /$ $\mathrm{min} / 1.73 \mathrm{~m}^{2}$, comprising $14.5 \%$ of the total patient 
population (both with and without T2D) [34]. The EMPEROR-reduced trial of empagliflozin for the treatment of heart failure in people with and without T2D also did not exclude patients with eGFR 20 to $<30 \mathrm{~mL} /$ $\min / 1.73 \mathrm{~m}^{2}$ [49]. The initial results from these studies suggest that the renoprotective effects of SGLT2 inhibitors can still be observed in patients with severe CKD.

\section{Other studies showing effects of SGLT2 inhibitors on specific renal outcomes \\ Effects on eGFR}

A number of studies have reported significant stabilization of eGFR following treatment with SGLT2 inhibitors, particularly in comparison with sulfonylureas glimepiride and glipizide [55-58]. A meta-analysis of 40 randomized trials, involving almost 30,000 patients, found that SGLT2 inhibition in patients with renal impairment was associated with an initial decline in eGFR, compared with placebo, which was followed by a return to baseline levels, whereas there was no significant change in eGFR in patients without renal impairment [59]. This meta-analysis was published prior to DECLARE TIMI-58 results, which demonstrated an initial decrease in eGFR compared to placebo in patients with and without renal impairment [36]. Some studies have reported slightly increased rates of renal impairment and renal failure events during SGLT2 inhibitor therapy. In the short term, greater declines in eGFR have been reported with dapagliflozin compared with placebo, after 12 weeks of treatment ( $-10.8 \%$ versus $-2.9 \%$, respectively) [60]. A further study reported a higher rate of renal failure events with dapagliflozin, compared with glipizide (5.9\% versus $3.4 \%$, respectively), the majority of which were manifested as reduced calculated renal creatinine clearance [58]. A study involving 808 low-risk people with T2D showed similar rates of renal impairment and renal failure in the placebo and dapagliflozin groups, although there was a tendency towards increasing rates with higher doses of dapagliflozin [61]. Another study reported higher rates of renal impairment and renal failure events with dapagliflozin $2.5 \mathrm{mg}$ and $5 \mathrm{mg}$ (4.4\% and $2.9 \%$, respectively), compared with placebo (1.5\%), although the incidence with dapagliflozin $10 \mathrm{mg}$ was equal to that with placebo [62]. A 24-week Japanese study of ipragliflozin in people with T2D reported larger changes in eGFR from baseline for ipragliflozin versus placebo in patients with moderate renal impairment (eGFR 30 to $<60 \mathrm{~mL}$ / $\min / 1.73 \mathrm{~m}^{2}$ ) compared with those with mild impairment (eGFR 60 to $<90 \mathrm{~mL} / \mathrm{min} / 1.73 \mathrm{~m}^{2} ;-2 \mathrm{~mL} / \mathrm{min} / 1.73$ $\mathrm{m}^{2}$ vs $-0.5 \mathrm{~mL} / \mathrm{min} / 1.73 \mathrm{~m}^{2}$ ) [63]. Other studies have reported no significant changes in eGFR during longer term treatment with empagliflozin [64-66], canagliflozin [67-69], dapagliflozin [60, 70, 71], ipragliflozin [72, 73], ertugliflozin [74], or tofogliflozin [75]. All SGLT2 inhibitor CVOTs report an initial rapid reduction in eGFR, followed by a slower decline, or stabilization, in the SGLT2 inhibitor group compared with placebo, explaining the greater decline in eGFR after 12 weeks that was reported in some studies. A meta-analysis including 48 studies of 34,661 patients treated with SGLT2 inhibitors (canagliflozin, dapagliflozin, empagliflozin, ipragliflozin, tofogliflozin) found substantial variation for the treatment impact on change in eGFR across included studies with duration $<52$ weeks in the short term, but demonstrated that SGLT2 inhibitors significantly slowed the decline in eGFR in patients with treatment duration $>52$ weeks [76].

\section{Effects on UACR}

In the EMPA-REG H2H-SU trial, the use of empagliflozin as an add-on to metformin was associated with a slight reduction in albuminuria progression, as measured by UACR, compared with glimepiride [55]. Regression of albuminuria in patients receiving empagliflozin, compared with glimepiride, as add-on therapy to metformin, was more pronounced in patients with higher albuminuria at baseline than in those with less impairment. The mean [standard deviation (SD)] changes in UACR from baseline in patients with normoalbuminuria were -6.7 (37.7) $\mathrm{mg} / \mathrm{g}$ and $8.6(72.6) \mathrm{mg} / \mathrm{g}$ for the empagliflozin and glimepiride groups, respectively; corresponding values were $-9.0(98.4) \mathrm{mg} / \mathrm{g}$ and $56.5(677.0) \mathrm{mg} / \mathrm{g}$, respectively, for those with microalbuminuria, and -483.5 (613.7) $\mathrm{mg} / \mathrm{g}$ and 380.1 (1161.5) $\mathrm{mg} / \mathrm{g}$, respectively, for those with macroalbuminuria [55].

In a 52-week, multicenter, randomized trial including 269 people with T2D and CKD stage 3, canagliflozin $100 \mathrm{mg}$ and $300 \mathrm{mg}$ resulted in larger decreases in UACR, compared with placebo, at week $26(-29.9 \%,-20.9 \%$, and $-7.5 \%$, respectively) [77]. Albuminuria progression rates from baseline to week 26 were significantly lower in canagliflozin-treated patients, compared with placebo, with odds ratios (ORs) of 0.33 (95\% CI 0.08, 1.48) for the $100 \mathrm{mg}$ dose and 0.51 (95\% CI 0.14, 1.91) for the $300 \mathrm{mg}$ dose [78]. At week 52, albuminuria regression rates in patients receiving canagliflozin $100 \mathrm{mg}$, canagliflozin $300 \mathrm{mg}$, or placebo were $15.4 \%, 20.6 \%$, and $11.4 \%$, respectively; these values were slightly higher than the corresponding albuminuria progression rates $(10.3 \%$, $14.7 \%$, and $17.1 \%$, respectively) [78]. In CANTATA-SU, UACR decreased with canagliflozin at both 52 weeks [mean (SD)] changes from baseline with canagliflozin $100 \mathrm{mg}$ and $300 \mathrm{mg}:-0.1$ [4.7] $\mathrm{g} / \mathrm{mol}$ and -0.9 [6.7] g/ mol, respectively) and 104 weeks $(-0.02 \mathrm{~g} / \mathrm{mol},-0.27 \mathrm{~g} /$ mol, respectively), but increased in glimepiride-treated patients (mean increase 0.7 [SD: 15.3] g/mol at week 52, and $1.55 \mathrm{~g} / \mathrm{mol}$ at week 104) [56]. 
Mean reductions in UACR in people with T2D receiving dapagliflozin or glipizide as add-on therapy to metformin have been reported as -19.0 [standard error (SE): 6.6] $\mathrm{mg} / \mathrm{g}$ and -0.8 (SE: 7.1 ) $\mathrm{mg} / \mathrm{g}$, respectively [58]. A Japanese study of 86 people with T2D also reported a substantial decrease in log-UACR of $0.37 \pm 0.73$ over 24 weeks, which was significantly associated with improvements in blood pressure [79]. In a separate posthoc analysis of 166 people with T2D with CKD stage 3 and albuminuria $(\geq 30 \mathrm{mg} / \mathrm{g})$, dapagliflozin treatment was associated with a change in UACR at week 104 of $-43.9 \%(95 \% \mathrm{CI}-64.3,-12.0)$ and $-26.4 \%(-55.0$, 20.5) at doses of $10 \mathrm{mg}$ and $5 \mathrm{mg}$, respectively, whereas UACR increased by $31.0 \%(-19.0,111.9)$ in the placebo group [80]. Another post-hoc analysis, using pooled data from two phase 3 trials, assessed people with T2D with inadequately controlled hypertension despite RAS inhibitor therapy. Dapagliflozin significantly reduced albuminuria by $33.2 \%$ ( $95 \%$ CI $-45.4,-18.2 \%$ ), compared with placebo, and the effect was similar in patients with baseline microalbuminuria $(-35.4 \%$; $95 \% \mathrm{CI}-48.8,-18.7 \%)$ or macroalbuminuria (-28.3\%; 95\% CI $-52.9,9.2 \%)$ [81].

In the DERIVE study, which investigated the effects of dapagliflozin in people with T2D and CKD stage 3a, dapagliflozin did not reduce UACR from baseline at week 24 in the overall population (difference versus placebo: $8.0 \%$; $95 \% \mathrm{CI}-14.4,36.3$ ). However, in patients with baseline UACR $\geq 30 \mathrm{mg} / \mathrm{g}$, dapagliflozin significantly reduced UACR from baseline at week 4 (mean treatment difference:-30.7\%; 95\% CI $-47.3,-8.9)$ and week 12 (mean treatment difference: $-41.7 \%$; $95 \%$ $\mathrm{CI}-57.1,-21.0)$, suggesting added benefit for patients with higher renal risk [82]. The DELIGHT study of people with $\mathrm{T} 2 \mathrm{D}$ and $\mathrm{UACR} \geq 30 \mathrm{mg} / \mathrm{g}$ also reported a decrease in UACR, compared with placebo, at week 24 in patients treated with dapagliflozin $(-21.0 \%$; $95 \%$ $\mathrm{CI}-34.1,-5.2)$ and a combination of dapagliflozin and saxagliptin $(-38.0 \%, 95 \% \mathrm{CI}-48.2,-25.8)$ [83]. In a pooled analysis of 11 phase 3 clinical trials in patients with no renal impairment or CKD stage 1-3a, dapagliflozin was associated with placebo-corrected reductions in UACR irrespective of baseline eGFR; however, in patients with $U A C R \geq 30 \mathrm{mg} / \mathrm{g}$ at baseline, the greatest reductions were seen in the subgroup of patients with the lowest eGFR ( $\geq 45$ to $<60 \mathrm{~mL} / \mathrm{min} / 1.73 \mathrm{~m}^{2}$ ) [84]. Similarly, in a pooled analysis of 11 randomized trials in patients with CKD stage $3 \mathrm{~b}-4$, dapagliflozin $5 \mathrm{mg}$ and $10 \mathrm{mg}$ led to changes in UACR of $-47.1 \%(95 \% \mathrm{CI}-64.8,-20.6)$ and $-38.4 \%$ (95\% CI $-57.6,-10.3$ ), respectively, compared with placebo [85]. Similar results were seen in the subgroup of patients with baseline UACR $\geq 30 \mathrm{mg} / \mathrm{g}$ and in subgroups stratified by median albumin concentrations at baseline. Various meta-analyses found that irrespective of the presence or absence of renal impairment, SGLT2 inhibitor therapy was associated with reductions in urine albumin and progression to macroalbuminuria [42, 59, 76].

In contrast to these positive results, some studies have found no significant benefit, in terms of markers of renal function, with SGLT2 inhibitors in people with T2D at low renal risk. An analysis of 12 randomized, doubleblind clinical trials involving 4545 patients found that more than $90 \%$ of patients, whose baseline renal function was largely preserved or only mildly compromised (eGFR $84.6-86.7 \mathrm{~mL} / \mathrm{min} / 1.73 \mathrm{~m}^{2}$ ), remained in the normal albuminuria category in both dapagliflozin and placebo groups, with the proportion of patients with worsening albuminuria at week 24 similar for dapagliflozin and placebo irrespective of baseline eGFR category (normal renal function and mild or moderate renal impairment) [29]. A dose-dependent increase in microalbuminuria has also been reported in a single phase 2 study with empagliflozin in people with T2D [86]. Over 24 weeks, treatment with ipragliflozin was also found to reduce UACR to a lesser degree in patients with mild renal impairment $(-1.28 \mathrm{mg} / \mathrm{g}$ versus placebo) compared with those with moderate impairment $(-55.18 \mathrm{mg} / \mathrm{g}$ versus placebo) [63]. In addition, dapagliflozin therapy was associated with a non-significant reduction in UACR compared to placebo [mean difference: $-17.0 \%$ (95\% CI - 33.2, 3.4)] in people with CKD without T2D [87].

\section{Effects of SGLT2 inhibitors on uric acid}

A systematic review found the following reductions in serum uric acid levels with SGLT2 inhibitors compared with placebo or standard care: canagliflozin weighed mean difference (WMD): $-36.72 \mu \mathrm{mol} / \mathrm{L} \quad(95 \% \mathrm{CI}$ $-38.12,-35.33)$, dapagliflozin WMD: $-38.05 \mu \mathrm{mol} / \mathrm{L}$ (95\% CI -44.47, - 31.62), and empagliflozin WMD: $-42.07 \mu \mathrm{mol} / \mathrm{L}(95 \% \mathrm{CI}-46.27,-37.86)$ [88] This is an important finding because studies with allopurinol and other uric acid-lowering agents have suggested that decreasing uric acid is itself renoprotective [89-93], with a number of potential mechanisms proposed, including the prevention of formation and subsequent adherence of uric acid crystals onto renal epithelial cells and the resulting inflammatory response [94], and the reduction of glomerular hypertension by preventing uric acid-induced vascular smooth muscle proliferation in the afferent arterioles $[95,96]$. In EMPA-REG H2H-SU, empagliflozin reduced uric acid levels by 52 (SD: 82 ) $\mu \mathrm{mol} / \mathrm{L}$ from baseline, whereas glimepiride-treated patients showed a mean increase of 16 (SD: 90) $\mu \mathrm{mol} / \mathrm{L}$ [55]. Likewise, in a study involving 814 people with T2D and low CV and renal risk, the use of dapagliflozin as add-on therapy to metformin was associated with a mean reduction of uric 
acid from baseline of 45.2 (SE: 3.4) $\mu \mathrm{mol} / \mathrm{L}$, compared with an increase of 16.1 (SE: 3.4) $\mu \mathrm{mol} / \mathrm{L}$ in glipizidetreated patients [58]. Similar results were obtained in a 102-week randomized study with dapagliflozin in lowrisk metformin-treated people with T2D [97]. Reductions in uric acid suggestive of improvements in kidney function have also been reported in a number of other studies with empagliflozin [64-66], canagliflozin [67-69, 98], and ipragliflozin [99]. However, other trials have reported no notable differences in various measures of renal function, including serum creatinine and uric acid, with canagliflozin $[69,98]$, dapagliflozin $[70,71]$, or tofogliflozin $[75,100]$.

One reason for these conflicting results might be that trials investigating low-risk patients may be unlikely to reach statistical significance, particularly in subgroup analyses and for secondary or exploratory endpoints, owing to low numbers of observed events and hence low statistical power for tested outcomes. As a result, these findings should be interpreted with caution.

\section{Potential renal benefits of SGLT2 inhibitors in the real-world setting}

While the results from clinical trials, including the CVOTs, provide important insights into the potential benefits of SGLT2 inhibitor therapy, restricted inclusion criteria may limit their generalizability to real-world people with T2D, especially those at the low end of the CV and renal risk spectrum. A European observational study found that the DECLARE-TIMI 58 study most closely resembles the common T2D population particularly in terms of CV risk profile, with 59\% representativeness, compared with $34 \%$ for the CANVAS program and $21 \%$ for EMPA-REG OUTCOME [101]. However, the proportion of people with T2D with low eGFR $(<60 \mathrm{~mL} /$ $\mathrm{min} / 1.73 \mathrm{~m}^{2}$ ) was $7.4 \%$ in DECLARE-TIMI 58 [23], 26\% in EMPA-REG OUTCOME [24], 16.4\% in CANVAS [102], and $22.8 \%$ in CANVAS-R [103], compared with $18.5 \%$ seen in UK general practice [80].

Real-world observational studies can provide important insights into the effectiveness of SGLT2 inhibitors in preventing mortality and morbidity in people with T2D across the entire renal risk spectrum. In general, the results of such studies support those of the major outcomes trials, even though in most countries, SGLT2 inhibitors are not prescribed in patients with eGFR $<60 \mathrm{~mL} / \mathrm{min} / 1.73 \mathrm{~m}^{2}$, limiting the possibility to extend these observations to a T2D population at higher renal risk. In people with T2D and hypertension, changes in albuminuria occurred in parallel with changes in adverse renal outcomes in an observational study [104], and other studies have shown that UACR is a strong predictor of albuminuria progression in people with T2D
[105]. Baseline prevalence of microalbuminuria and macroalbuminuria in EMPA-REG OUTCOME (28.7\% and $11 \%$, respectively) [30] and the CANVAS program (23\% and $8 \%$, respectively) [106] were also similar to that reported in real-world studies $[105,107]$.

CVD-REAL 3, a large-scale multinational, observational cohort study including data from 65,231 patients, compared outcomes following initiation of SGLT2 inhibitors (dapagliflozin, empagliflozin, canagliflozin, ipragliflozin, tofogliflozin, and luseogliflozin) with those following initiation of other glucose-lowering drugs (dipeptidyl peptidase-4 [DPP-4] inhibitors, insulin, glucagon-like peptide-1 receptor agonists [GLP-1 RAs], sulfonylurea, thiazolidinedione, metformin, metiglinides, and acarbose) in propensity-matched patient cohorts [108]. Consistent with what was observed in clinical trials, during the mean follow-up of 14.9 months, initiation of SGLT2 inhibitors was associated with a 51\% reduction in the risk of $50 \%$ eGFR decline or ESKD events, compared with other glucose-lowering drugs (HR: 0.49; 95\% CI 0.35, $0.67)$ [108]. There were no statistically significant differences in the relative risk reductions according to patient baseline eGFR or albuminuria status. SGLT2 inhibitor initiation was also associated with lower risk of hospitalization for heart failure (HR: $0.60 ; 95 \% \mathrm{CI} 0.47,0.76$ ) and all-cause mortality (HR: 0.55 ; 95\% CI 0.48, 0.64) [108]. Another recent real-world study, involving approximately 12,000 people with $\mathrm{T} 2 \mathrm{D}$, also investigated renal events following initiation of SGLT2 inhibitors $(n=6418)$ or DPP-4 inhibitors $(n=5604)$ [109]. Similar to the results of CVD-REAL 3, compared with DPP-4 inhibitors, SGLT2 inhibitor therapy was associated with decreased risks of $\geq 30 \%$ reduction in eGFR (OR: 0.70 ; $95 \%$ CI 0.49 , 1.00), AKI (OR: 0.47; 95\% CI 0.27, 0.80), hospitalization (OR: $0.66 ; 95 \%$ CI $0.56,0.78$ ), and all-cause mortality (OR: 0.43; 95\% CI 0.20, 0.95) [109].

A real-world Japanese study has investigated the renoprotective effects of SGLT2 inhibitors in 42 people with T2D and moderate-to-severe CKD (stage 3b-4) [110]. After 1 year, the annual decline in eGFR was significantly reduced by SGLT2 inhibitor therapy, as demonstrated by a median change in eGFR from $-3.8 \mathrm{~mL} / \mathrm{min} / 1.73$ $\mathrm{m}^{2} /$ year to $0.1 \mathrm{~mL} / \mathrm{min} / 1.73 \mathrm{~m}^{2} /$ year [110]. CVDREAL 3 also reported a that the rate of eGFR decline was $1.53 \mathrm{~mL} / \mathrm{min} / 1.73 \mathrm{~m}^{2} /$ year less in patients receiving SGLT2 inhibitors compared with those treated with other glucose-lowering therapies [108]. The Japanese study also found that SGLT2 inhibitor therapy was associated with a significant decrease in median UACR, from 0.36 to $0.23 \mathrm{~g} / \mathrm{g}$ creatinine [110]. Similarly, an Italian realworld study reported that, when adjusted for baseline differences between the groups, 6 months of treatment with dapagliflozin resulted in a reduction in albumin excretion 


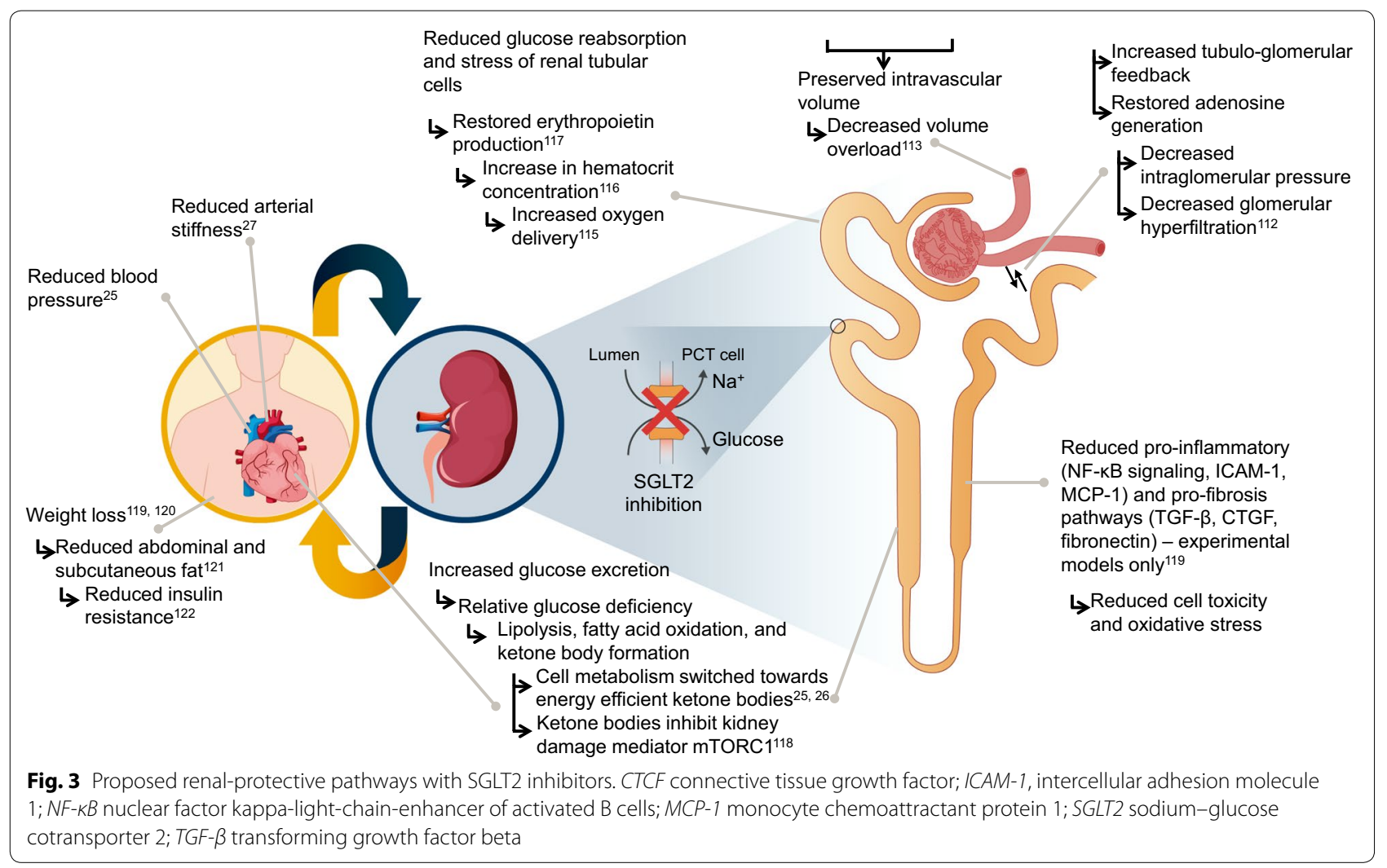

rate, which was $26.4 \mathrm{mg} / \mathrm{g}$ greater than that experienced by patients receiving other glucose-lowering medications (combined GLP-1 RAs, DPP-4 inhibitors, or gliclazide; $P=0.049$ ) [111].

\section{Mechanisms of renal benefits with SGLT2 inhibitors}

The inhibition of SGLT2 leads to tubuloglomerular feedback via enhanced natriuresis and delivery of sodium to the macula densa, thereby decreasing diabetic glomerular hyperfiltration due to hyperglycemia [112]. This is hypothesized to reduce the resulting chronic kidney damage (Fig. 3). In combination with the osmotic diuresis effect, natriuresis has also been postulated to preserve intravascular volume and decrease volume overload [113], although body fluid changes appear to be transitory [114]. Evidence from animal models suggests that SGLT2 inhibition reduces proinflammatory and profibrotic pathways, as well as tubular cell toxicity [115]. The significant increase in hematocrit concentration reported in patients receiving SGLT2 inhibitors [116] appears to be linked to increases in erythropoietin production [60, 117], which may also result in increased oxygen delivery to the kidney and reduction in renal hypoxia [115]. In addition, increased glucose excretion in the urine can lead to a state of relative glucose deficiency, triggering lipolysis in adipose tissue, fatty acid oxidation, and ketone body formation $[25,26]$. Ketone bodies are a more energy-efficient fuel in renal tubular cells than glucose, and as a result, renal oxygen consumption is reduced in the presence of mild ketosis; hence, it has been suggested that the use of ketone bodies as energy substrates in patients receiving SGLT2 inhibitors may contribute to the renoprotective effects of these agents, with a similar mechanism as in the myocardium [25, 26]. Ketone bodies have also been found to inhibit the mechanistic target of rapamycin complex 1, a mediator of kidney damage in animal models [118]. In addition to hemodynamic effects, SGLT2 inhibitors also have beneficial metabolic effects that may contribute to renoprotection. Treatment with SGLT2 inhibitors leads to significant weight loss of up to approximately $5 \mathrm{~kg}[119,120]$, two-thirds of which are accounted for by reductions in both abdominal and subcutaneous fat [121]. Indeed, after 6 months off treatment, weight loss has been found to be primarily due to loss of adipose tissue mass [114]. This fat mass loss can in turn lead to reductions in insulin resistance [122], metabolic risk [123], and renal risk [124].

The available SGLT2 inhibitors differ in their selectivity for SGLT2. While empagliflozin and dapagliflozin are highly selective for SGLT2, canagliflozin also inhibits SGLT1 to a small extent $[125,126]$. However, whether 
SGLT selectivity may contribute to different renal benefits is currently unclear.

\section{Renal outcomes in studies with SGLT2 inhibitors versus studies with GLP-1 RAs}

Both the GLP-1 RA and SGLT2 inhibitor classes have demonstrated significant glucose-lowering effects in people with T2D, with a low risk of hypoglycemia [127]. In addition, both have also shown significant benefits on renal outcomes. A reduction in the incidence of microvascular events (macroalbuminuria, doubling of serum creatinine, ESKD, or renal death) was reported with liraglutide, compared with placebo, in the LEADER CVOT (HR: 0.78; 95\% CI 0.67, 0.92); these effects were similar irrespective of baseline eGFR or albuminuria [21, 128]. However, this reduction was primarily driven by lower rates of new-onset persistent macroalbuminuria (HR: $0.74 ; 95 \%$ CI $0.60,0.91$ ) [128]. A reduction in the risk of new or worsening nephropathy (macroalbuminuria, doubling of serum creatinine, eGFR $<45 \mathrm{~mL} / \mathrm{min} / 1.73$ $\mathrm{m}^{2}$ ) with semaglutide compared with placebo was also reported in the SUSTAIN-6 CVOT (HR: 0.64; 95\% CI $0.46,0.88)$; again, this reduction was largely driven by reductions in macroalbuminuria (HR: $0.54 ; 95 \%$ CI 0.37 , 0.77) [20]. The REWIND CVOT comparing dulaglutide with placebo found a reduction in the risk of the composite renal outcome (macroalbuminuria, eGFR decline of $\geq 30 \%$, or chronic RRT; HR: 0.85 ; $95 \%$ CI $0.77,0.93$ ) following dulaglutide treatment, with a significant reduction in macroalbuminuria (HR: 0.77; 95\% CI 0.68, 0.87) [129]. Similar to liraglutide, a post-hoc analysis demonstrated that the impact of dulaglutide on the renal composite outcome did not appear to be influenced by baseline eGFR or albuminuria status, although dulaglutide appeared to only prevent the onset of new macroalbuminuria in patients with eGFR $<60 \mathrm{~mL} / \mathrm{min} / 1.73 \mathrm{~m}^{2}$ (HR: 0.70; 95\% CI 0.59, 0.81; $P$ for interaction $=0.046$ ) [130]. In addition, a sensitivity analysis found a $44 \%$ reduction in the number of patients with a sustained eGFR decline of $\geq 50 \%$ (HR: 0.56; 95\% CI 0.41, 0.76) in the dulaglutide arm compared with placebo [130]. Somewhat in contrast to these findings, AWARD-7, a randomized, open-label trial of people with T2D and moderate-to-severe CKD (stage 3-4) reported that dulaglutide reduced the decline in eGFR and albuminuria compared with insulin glargine, particularly in patients with macroalbuminuria at baseline [131].

In a meta-analysis that combined three SGLT2 inhibitor CVOTs with five trials of GLP-1 RAs involving 42,920 patients, both GLP-1 RAs and SGLT2 inhibitors significantly reduced the risk of progression of kidney disease including macroalbuminuria compared with placebo, with hazard ratios of $0.82(95 \%$ CI $0.75,0.89)$ and 0.62
(95\% CI 0.58, 0.67), respectively. The effect of SGLT2 inhibitors was significantly greater than that of GLP-1 RAs $(P=0.01$ for heterogeneity). Furthermore, the positive effect seen with GLP-1 RAs seemed to be largely confined to progression to macroalbuminuria, while SGLT2 inhibitors reduced the risk of worsening eGFR, ESKD, or death from kidney disease (HR: 0.55; 95\% CI $0.48,0.64)$; GLP-1 RAs had no significant effect on this particular composite (HR: 0.92; 95\% CI 0.80, 1.06) [132].

\section{Safety of SGLT2 inhibitors in T2D and renal impairment}

The CVOTs with SGLT2 inhibitors and meta-analyses of these trials have shown that SGLT2 inhibitors have a reassuring safety profile in people with $\mathrm{T} 2 \mathrm{D}$, and the realworld experience is consistent with this [133]. The principal adverse effects in CVOTs include genital and urinary tract infections, which are to be expected owing to the glycosuric effects resulting from SGLT2 inhibition; however, meta-analyses found increased rates of genital but not urinary tract infections; the absolute numbers were low and infections were usually easily managed $[44,45]$. There is also some evidence to suggest that combination treatment with SGLT2 inhibitors and DPP-4 inhibitors or GLP- RAs might reduce the incidence of such events [134, 135]. SGLT2 inhibitors produce a transient, dosedependent reduction in eGFR $[59,112]$, which is reversible on stopping treatment [136]; additionally, real-world data show that SGLT2 inhibitors are not associated with an increased risk of AKI [137, 138]. CVOT analyses actually show that there may be fewer AKI events in patients on SGLT2 inhibitor therapy compared with placebo [42]. Despite previous signals for increased diabetic ketoacidosis in people with T2D treated with SGLT2 inhibitors, the overall risk appears to be low [139-142]. Although the CANVAS program found that canagliflozin was associated with significant increases in the risks of amputations or fractures [22], no such findings have been reported in trials with other SGLT2 inhibitors [23, 24, 32], the CREDENCE renal outcomes trial with canagliflozin [33], or a recent cohort study [143]. Meta-analyses also confirmed no overall increase in amputation or fracture risk with SGLT2 inhibitors, but did highlight significant heterogeneity between trials $[44,45,144,145]$. Similarly, the use of SGLT2 inhibitors does not seem to be associated with increased rates of Fournier's gangrene (necrotizing fasciitis of the perineum); although six cases were reported in DECLARE-TIMI 58, five of these occurred in the placebo group [23, 133].

In a meta-analysis of 27 studies, including approximately 7300 patients, treatment with SGLT2 inhibitors in people with T2D and CKD was not associated with increased risks of adverse renal events (HR: 1.04; 95\% CI 
0.68, 1.61), AKI (HR: 0.69; 95\% CI 0.45, 1.06), or hyperkalemia (HR: 0.63 ; 95\% CI 0.48, 0.83), compared with controls [45]. Rates of hyperkalemia were also reduced in the CREDENCE trial of people with T2D and CKD (HR: 0.80; 95\% CI 0.65, 1.00) [33].

\section{Are renal outcomes with SGLT2 inhibition consistent in elderly patients?}

Theoretically, the effects of SGLT2 inhibitors might differ in elderly and younger patients, owing to age-related decline in $\mathrm{CV}$ and renal function. The adverse event profiles of SGLT2 inhibitors may be slightly more pronounced in elderly patients. An analysis of six randomized controlled trials with canagliflozin found that some adverse events occurred more frequently in elderly patients ( $>75$ years), with higher rates of osmotic diuresis-induced effects and urinary or genital mycotic infections [146]. In STELLA-ELDER, a Japanese postmarketing study of ipragliflozin in elderly patients (age $\geq 65$ years; $31 \%$ of patients were $>75$ years of age), $16.9 \%$ of patients experienced adverse events, most commonly skin and subcutaneous tissue disorders, and renal and urinary disorders [147]. In a subgroup analysis of the STELLA-LONG TERM study, the overall incidence of adverse events was similar in patients aged $<65$ years and in older patients (10.8\% versus $10.4 \%$, respectively), but the incidence of renal adverse events was significantly higher in older patients ( $0.5 \%$ versus $1.0 \%)$ [148].

Hypovolemia and dehydration may expose frail individuals to orthostatic hypotension or postural dizziness; it is therefore important to note that SGLT2 inhibitors do not induce a significant increase in sympathetic nerve activity in response to osmotic diuresis [149]. Hypotension and dehydration could potentially decrease renal filtration, leading to acute kidney failure that may be exacerbated by recurrent and/or unresolved kidney injury [150]. However, the current data are reassuring in this respect: after an initial decrease due to transient changes in renal hemodynamics, GFR stabilizes at values similar to baseline levels [30,98], even in patients with moderate eGFR impairment at baseline and in elderly individuals [85, 151-153]. Furthermore, the available evidence suggests that SGLT2 inhibitors are not associated with dehydration in elderly patients $[154,155]$.

\section{Conclusions}

The renoprotective effects of SGLT2 inhibitors do not seem to be influenced by baseline CV risk, including heart failure status. They are generally seen over a wide range of eGFR and albuminuria categories; however, it is difficult to elucidate whether these effects are greater in those with preserved or reduced renal function. In the EMPA-REG OUTCOME trial, the impact of empagliflozin treatment on the rates of acute renal failure and AKI was greatest in patients with baseline eGFR $<60 \mathrm{~mL} /$ $\mathrm{min} / 1.73 \mathrm{~m}^{2}$ [24]. In the CANVAS program, canagliflozin was shown to reduce renal outcomes consistently across different levels of baseline albuminuria, but with the largest absolute benefits in those with macroalbuminuria [53]. DECLARE-TIMI 58 demonstrated that dapagliflozin attenuated the increase in UACR over time to the greatest extent in patients with the highest degrees of albuminuria [36]. In the CREDENCE trial, there was greater risk reduction in the renal-specific outcome with canagliflozin compared with placebo, in patients with UACR $>1000 \mathrm{mg} / \mathrm{g}$ and in patients with an eGFR $<60 \mathrm{~mL} / \mathrm{min} / 1.73 \mathrm{~m}^{2}$ [33]. In a meta-analyses of these $\mathrm{CV}$ and renal outcome trials, the renoprotective effects of SGLT2 inhibitors were seen across all levels of baseline eGFR, although the largest benefits were apparent in patients with preserved renal function at baseline [42].

Studies such as CREDENCE, DERIVE, and DAPACKD offer a greater insight into the renoprotective effects of SGLT2 inhibitors in patients with moderate-to-severe CKD than the CVOTs that preceded them. In addition, real-world studies such as CVD-REAL 3 report similar results to those observed in CVOTs of SGLT2 inhibitor therapies in patient cohorts with an ample range of baseline renal function. Together, the outcomes of these trials demonstrate how the benefits of SGLT2 inhibitors, used in combination with RAS inhibitors, span the renal risk continuum, from patients with mild/moderate CKD (as seen in the EMPA-REG OUTCOME, CANVAS program, and DECLARE-TIMI 58 trials) to those with moderate/severe CKD (as observed in CREDENCE and DAPA-CKD). Results across studies vary, but overall, suggest that different clinically utilized therapeutic doses have similar efficacy in terms of renal outcomes. Further insights into the potential benefits of SGLT2 inhibitors in patients at different stages on the renal and $\mathrm{CV}$ risk continuum are likely to come from the EMPA-KIDNEY (NCT03594110) trial in patients with diabetic as well as nondiabetic CKD.

\footnotetext{
Abbreviations

AKI: Acute kidney injury; BMI: Body mass index; Cl: Confidence interval; CKD: Chronic kidney disease; CV: Cardiovascular; CVD: Cardiovascular disease; CVOT: Cardiovascular outcomes trials; DPP-4: Dipeptidyl peptidase-4; eGFR: Estimated glomerular filtration rate; ESKD: End-stage kidney disease; GFR: Glomerular filtration rate; GLP-1 RA: Glucagon-like peptide-1 receptor agonist; HR: Hazard ratio; NNT: Number needed to treat; OR: Odds ratio; RAS: Reninangiotensin system; RRT: Renal replacement therapy; SD: Standard deviation; SE: Standard error; SGLT2: Sodium-glucose cotransporter 2; T2D: Type 2 diabetes; UACR: Urinary albumin:creatinine ratio; UK: United Kingdom; UKPDS: UK Prospective Diabetes Study; WMD: Weighed mean difference.
} 


\section{Acknowledgements}

The authors would like to thank Dorothy Overington, PhD, and Maria Haughton, MSci, from integrated medhealth communication (imc), for providing medical writing support.

\section{Authors' contributions}

$F G$, JV, PF, and AS contributed to the review conception, article selection, interpretation, and revision of the manuscript. All authors read and approved the final manuscript.

\section{Funding}

Medical writing support for this project was funded by AstraZeneca.

\section{Availability of data and materials}

Data sharing is not applicable to this article as no datasets were generated or analyzed during the current study.

\section{Ethics approval and consent to participate}

Not applicable.

\section{Consent for publication}

Not applicable.

\section{Competing interests}

FG has received research support from Eli Lilly, Lifescan, and Takeda, and consultant fees from AstraZeneca, Boehringer-Ingelheim, Eli Lilly, Merck Sharp and Dohme, NovoNordisk, Roche Diabetes Care, and Sanofi. JV was a contractor acting as Chief Medical Advisor for cardiovascular, renal, and metabolic diseases at AstraZeneca at the time of manuscript development. PF is an employee of AstraZeneca. AS has received research grants from AstraZeneca and advisory board and speaker's fees from AstraZeneca, Boehringer Ingelheim, Lilly, Mundipharma, NovoNordisk, and Sanofi.

\section{Author details}

${ }^{1}$ Department of Emergency and Organ Transplantation, Section of Internal Medicine, Endocrinology, Andrology and Metabolic Diseases, University of Bari Aldo Moro, Policlinico, Piazza Giulio Cesare, 11, 70124 Bari, Italy. ${ }^{2}$ Diabetes and Endocrinology, University of Liverpool, Liverpool, UK. ${ }^{3}$ AstraZeneca, Cambridge, UK. ${ }^{4}$ Department of Surgical, Medical, Molecular and Critical Area Pathology, University of Pisa, Pisa, Italy.

Received: 4 August 2020 Accepted: 29 October 2020

Published online: 22 November 2020

\section{References}

1. Thomas MC, Cooper ME, Zimmet P. Changing epidemiology of type 2 diabetes mellitus and associated chronic kidney disease. Nat Rev Nephrol. 2016;12(2):73-81.

2. Arnold SV, Kosiborod M, Wang J, Fenici P, Gannedahl G, LoCasale RJ. Burden of cardio-renal-metabolic conditions in adults with type 2 diabetes within the Diabetes Collaborative Registry. Diabetes Obes Metab. 2018;20(8):2000-3.

3. Sattar N. Revisiting the links between glycaemia, diabetes and cardiovascular disease. Diabetologia. 2013;56(4):686-95.

4. Giorgino F, Vora J, Fenici P, Solini A. Cardiovascular protection with sodium-glucose co-transporter-2 inhibitors in type 2 diabetes: does it apply to all patients? Diabetes Obes Metab. 2020;12:68.

5. Adler Al, Stevens RJ, Manley SE, Bilous RW, Cull CA, Holman RR, et al. Development and progression of nephropathy in type 2 diabetes: the United Kingdom Prospective Diabetes Study (UKPDS 64). Kidney Int. 2003;63(1):225-32.

6. Brenner BM, Cooper ME, de Zeeuw D, Keane WF, Mitch WE, Parving $\mathrm{HH}$, et al. Effects of losartan on renal and cardiovascular outcomes in patients with type 2 diabetes and nephropathy. N Engl J Med. 2001;345(12):861-9.

7. Lewis EJ, Hunsicker LG, Clarke WR, BerlT, Pohl MA, Lewis JB, et al. Renoprotective effect of the angiotensin-receptor antagonist irbesartan in patients with nephropathy due to type 2 diabetes. N Engl J Med. 2001;345(12):851-60.
8. Parving $\mathrm{HH}$, Lehnert $\mathrm{H}$, Brochner-Mortensen J, Gomis R, Andersen $S$, Arner $P$, et al. The effect of irbesartan on the development of diabetic nephropathy in patients with type 2 diabetes. N Engl J Med. 2001;345(12):870-8.

9. Lou QL, Ouyang XJ, Gu LB, Mo YZ, Ma R, Nan J, et al. Chronic kidney disease and associated cardiovascular risk factors in chinese with type 2 diabetes. Diabetes Metab J. 2012;36(6):433-42.

10. Parving HH, Lewis JB, Ravid M, Remuzzi G, Hunsicker LG. Prevalence and risk factors for microalbuminuria in a referred cohort of type II diabetic patients: a global perspective. Kidney Int. 2006;69(11):2057-63.

11. Turin TC, Tonelli M, Manns BJ, Ravani P, Ahmed SB, Hemmelgarn BR. Chronic kidney disease and life expectancy. Nephrol Dial Transplant. 2012:27(8):3182-6.

12. Go AS, Chertow GM, Fan D, McCulloch CE, Hsu CY. Chronic kidney disease and the risks of death, cardiovascular events, and hospitalization. N Engl J Med. 2004;351(13):1296-305.

13. Bongartz LG, Cramer MJ, Doevendans PA, Joles JA, Braam B. The severe cardiorenal syndrome: "Guyton revisited." Eur Heart J. 2005;26(1):11-7.

14. UK Prospective Diabetes Study (UKPDS) Group. Intensive blood-glucose control with sulphonylureas or insulin compared with conventional treatment and risk of complications in patients with type 2 diabetes (UKPDS 33). UK Prospective Diabetes Study (UKPDS) Group. Lancet. 1998;352(9131):837-53.

15. Duckworth W, Abraira C, Moritz T, Reda D, Emanuele N, Reaven PD, et al. Glucose control and vascular complications in veterans with type 2 diabetes. N Engl J Med. 2009;360(2):129-39.

16. Gerstein HC, Miller ME, Byington RP, Goff DCJ, Bigger JT, Buse JB, et al. Effects of intensive glucose lowering in type 2 diabetes. N Engl J Med. 2008;358(24):2545-59.

17. Patel A, MacMahon S, Chalmers J, Neal B, Billot L, et al. Intensive blood glucose control and vascular outcomes in patients with type 2 diabetes. N Engl J Med. 2008;358(24):2560-72.

18. Zoungas S, Arima H, Gerstein HC, Holman RR, Woodward M, Reaven P, et al. Effects of intensive glucose control on microvascular outcomes in patients with type 2 diabetes: a meta-analysis of individual participant data from randomised controlled trials. Lancet Diabetes Endo. 2017;5(6):431-7.

19. Holman RR, Bethel MA, Mentz RJ, Thompson VP, Lokhnygina Y, Buse JB, et al. Effects of once-weekly exenatide on cardiovascular outcomes in type 2 diabetes. N Engl J Med. 2017;377(13):1228-39.

20. Marso SP, Bain SC, Consoli A, Eliaschewitz FG, Jodar E, Leiter LA, et al. Semaglutide and cardiovascular outcomes in patients with type 2 diabetes. N Engl J Med. 2016;375(19):1834-44.

21. Marso SP, Daniels GH, Brown-Frandsen K, Kristensen P, Mann JF, Nauck MA, et al. Liraglutide and cardiovascular outcomes in type 2 diabetes. $\mathrm{N}$ Engl J Med. 2016;375(4):311-22.

22. Neal B, Perkovic V, Mahaffey KW, de Zeeuw D, Fulcher G, Erondu N, et al. Canagliflozin and cardiovascular and renal events in type 2 diabetes. $\mathrm{N}$ Engl J Med. 2017;377(7):644-57.

23. Wiviott SD, Raz I, Bonaca MP, Mosenzon O, Kato ET, Cahn A, et al. Dapagliflozin and cardiovascular outcomes in type 2 diabetes. N Engl J Med. 2019;380(4):347-57.

24. Zinman B, Wanner C, Lachin JM, Fitchett D, Bluhmki E, Hantel S, et al. Empagliflozin, cardiovascular outcomes, and mortality in type 2 diabetes. N Engl J Med. 2015;373:2117-28.

25. Kashiwagi A, Maegawa H. Metabolic and hemodynamic effects of sodium-dependent glucose cotransporter 2 inhibitors on cardio-renal protection in the treatment of patients with type 2 diabetes mellitus. J Diabetes Investig. 2017;8(4):416-27.

26. Vallon $\mathrm{V}$, Thomson SC. Targeting renal glucose reabsorption to treat hyperglycaemia: the pleiotropic effects of SGLT2 inhibition. Diabetologia. 2017:60(2):215-25.

27. Chilton R, Tikkanen I, Cannon CP, Crowe S, Woerle HJ, Broedl UC, et al. Effects of empagliflozin on blood pressure and markers of arterial stiffness and vascular resistance in patients with type 2 diabetes. Diabetes Obes Metab. 2015;17(12):1180-93.

28. Tanaka H, Takano K, lijima H, Kubo H, Maruyama N, Hashimoto T, et al. Factors affecting canagliflozin-induced transient urine volume increase in patients with type 2 diabetes mellitus. Adv Ther. 2017;34(2):436-51. 
29. Kohan DE, Fioretto P, Johnsson K, Parikh S, Ptaszynska A, Ying L. The effect of dapagliflozin on renal function in patients with type 2 diabetes. J Nephrol. 2016;29(3):391-400.

30. Wanner C, Inzucchi SE, Lachin JM, Fitchett D, von Eynatten M, Mattheus $M$, et al. Empagliflozin and progression of kidney disease in type 2 diabetes. N Engl J Med. 2016;375(4):323-34.

31. Kluger AY, Tecson KM, Lee AY, Lerma EV, Rangaswami J, Lepor NE, et al. Class effects of SGLT2 inhibitors on cardiorenal outcomes. CardiovasC Diabetol. 2019;18(1):99.

32. Cannon CP, Pratley R, Dagogo-Jack S, Mancuso J, Huyck S, Masiukiewicz $\mathrm{U}$, et al. Cardiovascular outcomes with ertugliflozin in type 2 diabetes. New Engl J Med. 2020;28:96.

33. Perkovic V, Jardine MJ, Neal B, Bompoint S, Heerspink HJL, Charytan DM, et al. Canagliflozin and renal outcomes in type 2 diabetes and nephropathy. N Engl J Med. 2019;380(24):2295-306.

34. Heerspink HJL, Stefánsson BV, Correa-Rotter R, Chertow GM, Greene T, Hou F-F, et al. Dapagliflozin in patients with chronic kidney disease. N Engl J Med. 2020;28:457.

35. Fitchett $D$, Butler J, van de Borne P, Zinman B, Lachin JM, Wanner C, et al. Effects of empagliflozin on risk for cardiovascular death and heart failure hospitalization across the spectrum of heart failure risk in the EMPA-REG OUTCOME(R) trial. Eur Heart J. 2018;39(5):363-70.

36. Mosenzon O, Wiviott SD, Cahn A, Rozenberg A, Yanuv I, Goodrich $\mathrm{EL}$, et al. Effects of dapagliflozin on development and progression of kidney disease in patients with type 2 diabetes: an analysis from the DECLARE-TIMI 58 randomised trial. Lancet Diabetes Endocrinol. 2019;7(8):606-17.

37. Neuen BL, Ohkuma T, Neal B, Matthews DR, de Zeeuw D, Mahaffey KW, et al. Cardiovascular and renal outcomes with canagliflozin according to baseline kidney function. Circulation. 2018;138(15):1537-50.

38. Wheeler DC, Stefansson BV, Batiushin M, Bilchenko O, Cherney DZI, Chertow GM, et al. The dapagliflozin and prevention of adverse outcomes in chronic kidney disease (DAPA-CKD) trial: baseline characteristics. Nephrol Dial Transplant. 2020;35(10):1700-11.

39. Ras I, Wivicott SD, Yanuv I, Rozenberg A, Zelniker TA, Cahn A, et al. 244OR: Effects of dapagliflozin on the urinary albumin-to-creatinine ratio in patients with type 2 diabetes: a predefined analysis from the DECLARETIMI 58 randomised, placebo-controlled trial. Diabetes. 2019;68:244.

40. Jardine MJ, Mahaffey KW, Neal B, Agarwal R, Bakris GL, Brenner BM, et al. The Canagliflozin and renal endpoints in diabetes with established nephropathy clinical evaluation (CREDENCE) study rationale, design, and baseline characteristics. Am J Nephrol. 2017;46(6):462-72.

41. Phase 3 CREDENCE renal outcomes trial of INVOKANA ${ }^{\circledR}$ (canagliflozin) is being stopped early for positive efficacy findings. https://www.janss en.com/phase-3-credence-renal-outcomes-trial-invokanar-canagliflo zin-being-stopped-early-positive-efficacy2018.

42. Neuen BL, Young T, Heerspink HJL, Neal B, Perkovic V, Billot L, et al. SGLT2 inhibitors for the prevention of kidney failure in patients with type 2 diabetes: a systematic review and meta-analysis. Lancet Diabetes Endocrinol. 2019;7(11):845-54.

43. Lo KB, Gul F, Ram P, Kluger AY, Tecson KM, McCullough PA, et al. The effects of SGLT2 inhibitors on cardiovascular and renal outcomes in diabetic patients: a systematic review and meta-analysis. Cardiorenal Med. 2020;10(1):1-10.

44. Zelniker TA, Wiviott SD, Raz I, Im K, Goodrich EL, Bonaca MP, et al. SGLT2 inhibitors for primary and secondary prevention of cardiovascular and renal outcomes in type 2 diabetes: a systematic review and metaanalysis of cardiovascular outcome trials. Lancet. 2019;393(10166):31-9.

45. Toyama T, Neuen BL, Jun M, Ohkuma T, Neal B, Jardine MJ, et al. Effect of SGLT2 inhibitors on cardiovascular, renal and safety outcomes in patients with type 2 diabetes mellitus and chronic kidney disease: A systematic review and meta-analysis. Diabetes Obes Metab. 2019;21(5):1237-50.

46. Shi FH, Li H, Yue J, Jiang YH, Gu ZC, Ma J, et al. Clinical adverse events of high-dose vs low-dose sodium-glucose cotransporter 2 inhibitors in type 2 diabetes: a meta-analysis of 51 randomized clinical trials. J Clin Endocrinol Metabol. 2020;105:11.

47. Rådholm K, Figtree G, Perkovic V, Solomon SD, Mahaffey KW, Zeeuw D, et al. Canagliflozin and heart failure in type 2 diabetes mellitus results from the CANVAS Program (Canagliflozin Cardiovascular Assessment Study). Circulation. 2018;137:18.
48. McMurray JJV, Solomon SD, Inzucchi SE, Kober L, Kosiborod MN, Martinez FA, et al. Dapagliflozin in patients with heart failure and reduced ejection fraction. N Engl J Med. 2019;381(21):1995-2008.

49. Packer M, Anker SD, Butler J, Filippatos G, Pocock SJ, Carson P, et al. Cardiovascular and renal outcomes with empagliflozin in heart failure. N Engl J Med. 2020;26:87.

50. Furtado RHM, Bonaca MP, Raz I, Zelniker TA, Mosenzon O, Cahn A, et al. Dapagliflozin and cardiovascular outcomes in patients with type 2 diabetes mellitus and previous myocardial infarction. Circulation. 2019;139(22):2516-27.

51. Perkovic V, de Zeeuw D, Mahaffey KW, Fulcher G, Erondu N, Shaw W, et al. Canagliflozin and renal outcomes in type 2 diabetes: results from the CANVAS program randomised clinical trials. Lancet Diabetes Endocrinol. 2018;6(9):691-704

52. Cherney DZI, Zinman B, Inzucchi SE, Koitka-Weber A, Mattheus M, von Eynatten $M$, et al. Effects of empagliflozin on the urinary albuminto-creatinine ratio in patients with type 2 diabetes and established cardiovascular disease: an exploratory analysis from the EMPA-REG OUTCOME randomised, placebo-controlled trial. Lancet Diabetes Endo. 2017:5(8):610-21.

53. Neuen BL, Ohkuma T, Neal B, Matthews DR, de Zeeuw D, Mahaffey $\mathrm{KW}$, et al. Effect of canagliflozin on renal and cardiovascular outcomes across different levels of albuminuria: data from the CANVAS program. $J$ Am Soc Nephrol. 2019;30(11):2229-42.

54. Jardine MJ, Zhou Z, Mahaffey KW, Oshima M, Agarwal R, Bakris G, et al. Renal, cardiovascular, and safety outcomes of canagliflozin by baseline kidney function: a secondary analysis of the credence randomized trial. J Am Soc Nephrol. 2020;31(5):1128-39.

55. Ridderstråle M, Andersen KR, Zeller C, Kim G, Woerle HJ, Broedl UC, et al. Comparison of empagliflozin and glimepiride as add-on to metformin in patients with type 2 diabetes: a 104-week randomised, activecontrolled, double-blind, phase 3 trial. Lancet Diabetes Endocrinol. 2014:2(9):691-700.

56. Cefalu WT, Leiter LA, Yoon KH, Arias P, Niskanen L, Xie J, et al. Efficacy and safety of canagliflozin versus glimepiride in patients with type 2 diabetes inadequately controlled with metformin (CANTATA-SU): 52 week results from a randomised, double-blind, phase 3 non-inferiority trial. Lancet. 2013;382(9896):941-50.

57. Leiter LA, Yoon K-H, Arias P, Langslet G, Xie J, Balis DA, et al. Canagliflozin provides durable glycemic improvements and body weight reduction over 104 weeks versus glimepiride in patients with type 2 diabetes on metformin: a randomized, double-blind, phase 3 study. Diabetes Care. 2015;38(3):355-64.

58. Nauck MA, Del Prato S, Meier JJ, Durán-García S, Rohwedder K, Elze $M$, et al. Dapagliflozin versus glipizide as add-on therapy in patients with type 2 diabetes who have inadequate glycemic control with metformin. Diabetes Care. 2011;34(9):2015-22.

59. Seidu S, Kunutsor SK, Cos X, Gillani S, Khunti K. SGLT2 inhibitors and renal outcomes in type 2 diabetes with or without renal impairment: a systematic review and meta-analysis. Primary Care Diabetes. 2018;12(3):265-83.

60. Lambers Heerspink HJ, de Zeeuw D, Wie L, Leslie B, List J. Dapagliflozin a glucose-regulating drug with diuretic properties in subjects with type 2 diabetes. Diabetes Obes Metab. 2013;15(9):853-62.

61. Wilding J, Woo V, Rohwedder K, Sugg J, Parikh S. Dapagliflozin in patients with type 2 diabetes receiving high doses of insulin: efficacy and safety over 2 years. Diabetes Obes Metab. 2014;16(2):124-36.

62. Bailey CJ, Gross JL, Hennicken D, lqbal N, Mansfield TA, List JF. Dapagliflozin add-on to metformin in type 2 diabetes inadequately controlled with metformin: a randomized, double-blind, placebo-controlled 102week trial. BMC Med. 2013;11:43.

63. Kashiwagi A, Takahashi H, Ishikawa H, Yoshida S, Kazuta K, Utsuno A, Ueyama E. A randomized, double-blind, placebo-controlled study on long-term efficacy and safety of ipragliflozin treatment in patients with type 2 diabetes mellitus and renal impairment: results of the long-term ASP1941 safety evaluation in patients with type 2 diabetes with renal impairment (LANTERN) study. Diabetes Obes Metab. 2015;17(2):152-60.

64. Kovacs CS, Seshiah V, Swallow R, Jones R, Rattunde H, Woerle HJ, et al. Empagliflozin improves glycaemic and weight control as add-on therapy to pioglitazone or pioglitazone plus metformin in patients 
with type 2 diabetes: a 24-week, randomized, placebo-controlled trial. Diabetes Obes Metab. 2014;16:147-58.

65. Roden M, Weng J, Eilbracht J, Delafont B, Kim G, Woerle HJ, et al. Empagliflozin monotherapy with sitagliptin as an active comparator in patients with type 2 diabetes: a randomised, double-blind, placebocontrolled, phase 3 trial. Lancet Diabetes Endo. 2013;1 (3):208-19.

66. Häring HU, Merker L, Seewaldt-Becker E, Weimer M, Meinicke T, Broedl $U C$, et al. Empagliflozin as add-on to metformin in patients with type 2 diabetes: a 24-week, randomized, double-blind, placebo-controlled trial. Diabetes Care. 2014;37(6):1650-9.

67. Lavalle-González FJ, Januszewicz A, Davidson J, Tong C, Qiu R, Canovatchel $W$, et al. Efficacy and safety of canagliflozin compared with placebo and sitagliptin in patients with type 2 diabetes on background metformin monotherapy: a randomised trial. Diabetologia. 2013;56(12):2582-92.

68. Schernthaner G, Gross J, Rosenstock J, Guarisco M, Fu M, Yee J, et al. Canagliflozin compared with sitagliptin for patients with type 2 diabetes who do not have adequate glycemic control with metformin plus sulfonylurea: a 52-week randomized trial. Diabetes Care. 2013;36(9):2508-15.

69. Forst T, Guthrie R, Goldenberg R, Yee J, Vijapurkar U, Meininger G, Stein P. Efficacy and safety of canagliflozin over 52 weeks in patients with type 2 diabetes on background metformin and pioglitazone. Diabetes Obes Metab. 2014;16(5):467-77.

70. Ji L, Ma J, Li H, Mansfield TA, Tjoen CL, lqbal N, et al. Dapagliflozin as monotherapy in drug-naive Asian patients with type 2 diabetes mellitus: a randomized, blinded, prospective phase III study. Clin Ther. 2014;36(1):84-100.

71. Frías J, Guja C, Hardy E, Ahmed A, Dong F, Öhman P, Jabbour SA. Exenatide once weekly plus dapagliflozin once daily versus exenatide or dapagliflozin alone in patients with type 2 diabetes inadequately controlled with metformin monotherapy (DURATION-8): a 28 week, multicentre, double-blind, phase 3, randomised controlled trial. Lancet Diabetes Endo. 2016;4(12):1004-16.

72. Ishihara H, Yamaguchi S, Nakao I, Okitsu A, Asahina S. Efficacy and safety of ipragliflozin as add-on therapy to insulin in Japanese patients with type 2 diabetes mellitus (IOLITE): a multi-centre, randomized, placebocontrolled, double-blind study. Diabetes Obes Metab. 2016;18:12.

73. Nagai Y, Ohta A, Sada Y, Kato H, Tanaka Y. Effect of 24-week treatment with ipragliflozin on proinsulin/C-peptide ratio in Japanese patients with type 2 diabetes. Expert Opin Pharmacother. 2017;18(1):13-7.

74. Cherney DZI, Heerspink HJL, Frederich R, Maldonado M, Liu J, Pong A, et al. Effects of ertugliflozin on renal function over 104 weeks of treatment: a post hoc analysis of two randomised controlled trials. Diabetologia. 2020;63(6):1128-40.

75. Kaku K, Watada H, Iwamoto Y, Utsunomiya K, Terauchi Y, Tobe K, et al. Cardiovasc Diabetol. 2014;13:65.

76. Bae JH, Park E-G, Kim S, Kim SG, Hahn S, Kim NH. Effects of Sodiumglucose cotransporter 2 inhibitors on renal outcomes in patients with type 2 diabetes: a systematic review and meta-analysis of randomized controlled trials. Sci Rep. 2019;9(1):13009

77. Yale JF, Bakris G, Cariou B, Nieto J, David-Neto E, Yue D, et al. Efficacy and safety of canagliflozin over 52 weeks in patients with type 2 diabetes mellitus and chronic kidney disease. Diabetes Obes Metab. 2014;16(10):1016-27.

78. Yale JF, Bakris G, Cariou B, Yue D, David-Neto E, Xi L, et al. Efficacy and safety of canagliflozin in subjects with type 2 diabetes and chronic kidney disease. Diabetes Obes Metab. 2013;15(5):463-73.

79. Kinguchi S, Wakui H, Ito Y, Kondo Y, Azushima K, Osada U, et al. Improved home BP profile with dapagliflozin is associated with amelioration of albuminuria in Japanese patients with diabetic nephropathy: the Yokohama add-on inhibitory efficacy of dapagliflozin on albuminuria in Japanese patients with type 2 diabetes study (Y-AIDA study). Cardiovasc Diabetol. 2019;18(1):110.

80. Fioretto P, Stefansson BV, Johnsson E, Cain VA, Sjostrom CD. Dapagliflozin reduces albuminuria over 2 years in patients with type 2 diabetes mellitus and renal impairment. Diabetologia. 2016;59(9):2036-9.

81. Heerspink HJ, Johnsson E, Gause-Nilsson I, Cain VA, Sjostrom CD. Dapagliflozin reduces albuminuria in patients with diabetes and hypertension receiving renin-angiotensin blockers. Diabetes Obes Metab. 2016:18(6):590-7.
82. Fioretto P, Del Prato S, Buse JB, Goldenberg R, Giorgino F, Reyner D, et al. Efficacy and safety of dapagliflozin in patients with type 2 diabetes and moderate renal impairment (chronic kidney disease stage $3 \mathrm{~A}$ ): The DERIVE Study. Diabetes Obes Metab. 2018;20(11):2532-40.

83. Pollock C, Stefansson B, Reyner D, Rossing P, Sjostrom CD, Wheeler DC et al. Albuminuria-lowering effect of dapagliflozin alone and in combination with saxagliptin and effect of dapagliflozin and saxagliptin on glycaemic control in patients with type 2 diabetes and chronic kidney disease (DELIGHT): a randomised, double-blind, placebo-controlled trial. Lancet Diabetes Endocrinol. 2019;7(6):429-41.

84. Petrykiv S, Sjöström CD, Greasley PJ, Xu J, Persson F, Heerspink HJL. Differential effects of dapagliflozin on cardiovascular risk factors at varying degrees of renal function. Clin J Am Soc Nephrol. 2017;12(5):751-9.

85. Dekkers CCJ, Wheeler DC, Sjostrom CD, Stefansson BV, Cain V, Heerspink HJL. Effects of the sodium-glucose co-transporter 2 inhibitor dapagliflozin in patients with type 2 diabetes and Stages $3 \mathrm{~b}-4$ chronic kidney disease. Nephrol Dial Transplant. 2018;33(11):2005-11.

86. Ferrannini E, Seman L, Seewaldt-Becker E, Hantel S, Pinnetti S, Woerle H. A Phase llb, randomized, placebo-controlled study of the SGLT2 inhibitor empagliflozin in patients with type 2 diabetes. Diabetes Obes Metab. 2013;15(8):721-8.

87. Cherney DZI, Dekkers CCJ, Barbour SJ, Cattran D, Abdul Gafor AH, Greasley PJ, et al. Effects of the SGLT2 inhibitor dapagliflozin on proteinuria in non-diabetic patients with chronic kidney disease (DIAMOND): a randomised, double-blind, crossover trial. Lancet Diabetes Endocrinol. 2020;8(7):582-93.

88. Xin Y, Guo Y, Li Y, Ma Y, Li L, Jiang H. Effects of sodium glucose cotransporter-2 inhibitors on serum uric acid in type 2 diabetes mellitus: a systematic review with an indirect comparison meta-analysis. Saudi J Biol Sci. 2019;26(2):421-6.

89. Bose B, Badve SV, Hiremath SS, Boudville N, Brown FG, Cass A, et al. Effects of uric acid-lowering therapy on renal outcomes: a systematic review and meta-analysis. Nephrol Dial Transplant. 2014;29(2):406-13.

90. Kim S, Kim HJ, Ahn HS, Oh SW, Han KH, Um TH, et al. Renoprotective effects of febuxostat compared with allopurinol in patients with hyperuricemia: a systematic review and meta-analysis. Kidney Res Clin Pract. 2017;36(3):274-81.

91. Su X, Xu B, Yan B, Qiao X, Wang L. Effects of uric acid-lowering therapy in patients with chronic kidney disease: a meta-analysis. PLOS ONE. 2017;12(11):e0187550.

92. Wada T, Hosoya T, Honda D, Sakamoto R, Narita K, Sasaki T, et al. Uric acid-lowering and renoprotective effects of topiroxostat, a selective xanthine oxidoreductase inhibitor, in patients with diabetic nephropathy and hyperuricemia: a randomized, double-blind, placebocontrolled, parallel-group study (UPWARD study). Clin Exp Nephrol. 2018;22(4):860-70.

93. Liu X, Zhai T, Ma R, Luo C, Wang H, Liu L. Effects of uric acid-lowering therapy on the progression of chronic kidney disease: a systematic review and meta-analysis. Ren Fail. 2018:40(1):289-97.

94. Khan SR. Crystal-induced inflammation of the kidneys: results from human studies, animal models, and tissue-culture studies. Clin Exp Nephrol. 2004;8(2):75-88.

95. Mazzali M, Kanellis J, Han L, Feng L, Xia YY, Chen Q, et al. Hyperuricemia induces a primary renal arteriolopathy in rats by a blood pressure-independent mechanism. Am J Physiol Renal Physiol. 2002;282(6):F991-7.

96. Sánchez-Lozada LG, Tapia E, Avila-Casado C, Soto V, Franco M, Santamaría J, et al. Mild hyperuricemia induces glomerular hypertension in normal rats. Am J Physiol Renal Physiol. 2002;283(5):F1105-10.

97. Bailey C, Gross JL, Pieters A, Bastien A, List JF. Effect of dapagliflozin in patients with type 2 diabetes who have inadequate glycaemic control with metformin: a randomised, double-blind, placebo-controlled trial. Lancet. 2010;375(9733):2223-33.

98. Bode B, Stenlof K, Harris S, Sullivan D, Fung A, Usiskin K, et al. Longterm efficacy and safety of canagliflozin over 104 weeks in patients aged 55-80 years with type 2 diabetes. Diabetes Obes Metab. 2015;17(3):294-303.

99. Wilding JP, Ferrannini E, Fonseca VA, Wilpshaar W, Dhanjal P, Houzer A. Efficacy and safety of ipragliflozin in patients with type 2 diabetes inadequately controlled on metformin: a dose-finding study. Diabetes Obes Metab. 2013;15(55):403-9. 
100. Ikeda S, Takano Y, Cynshi O, Tanaka R, Christ A, Boerlin V, et al. A novel and selective sodium-glucose cotransporter-2 inhibitor, tofogliflozin, improves glycaemic control and lowers body weight in patients with type 2 diabetes mellitus. Diabetes Obes Metab. 2015;17(10):984-93.

101. Birkeland KI, Bodegard J, Norhammar A, Kuiper JG, Georgiado E, Beekman-Hendriks WL, et al. How representative of a general type 2 diabetes population are patients included in cardiovascular outcome trials with SGLT2 inhibitors? A large European observational study. Diabetes Obes Metab. 2019;21(4):968-74.

102. Neal B, Perkovic V, Matthews DR, Mahaffey KW, Fulcher G, Meininger G, et al. Rationale, design and baseline characteristics of the CANagliflozin cardioVascular Assessment Study-Renal (CANVAS-R): A randomized, placebo-controlled trial. Diabetes Obes Metab. 2017;19(3):387-93.

103. Neal B, Perkovic V, de Zeeuw D, Mahaffey KW, Fulcher G, Stein P, et al. Rationale, design, and baseline characteristics of the Canagliflozin Cardiovascular Assessment Study (CANVAS)-a randomized placebocontrolled trial. Am Heart J. 2013;166(2):217-23.

104. Viazzi F, Ceriello A, Fioretto P, Giorda C, Guida P, Russo G, et al. Changes in albuminuria and renal outcome in patients with type 2 diabetes and hypertension: a real-life observational study. J Hypertens. 2018;22:69.

105. John L, Rao S, Kanagasabapathy AS. Rate of progression of albuminuria in type ii diabetes five-year prospective study from South India. Diabetes Care. 1994;17(8):888-90.

106. De Zeeuw D. 77th Scientific Session of the American Diabetes Association 9th-13th June 2017; San Diego, CA, USA: The Integrated Results of the CANVAS Program. Drugs Today (Barc). 2017;53(7):405-13.

107. Tapp RJ, Dip G, Shaw JE, Zimmet PZ, Balkau B, Chadban SJ, et al. Albuminuria is evident in the early stages of diabetes onset: results from the australian diabetes, obesity, and lifestyle study (AusDiab). Am J Kidney Dis. 2004;44(5):792-8.

108. Heerspink HJL, Karasik A, Thuresson M, Melzer-Cohen C, Chodick G, Khunti K, et al. Kidney outcomes associated with use of SGLT2 inhibitors in real-world clinical practice (CVD-REAL 3): a multinational observational cohort study. Lancet Diabetes Endo. 2020;8(1):27-35.

109. Cahn A, Melzer-Cohen C, Pollack R, Chodick G, Shalev V. Acute renal outcomes with sodium-glucose co-transporter-2 inhibitors: Real-world data analysis. Diabetes Obes Metab. 2019;21(2):340-8.

110. Sugiyama S, Jinnouchi H, Yoshida A, Hieshima K, Kurinami N, Jinnouchi K, et al. Renoprotective effects of additional SGLT2 inhibitor therapy in patients with type 2 diabetes mellitus and chronic kidney disease stages $3 b-4$ : a real world report from a japanese specialized diabetes care center. J Clin Med Res. 2019;11(4):267-74.

111. Fadini GP, Solini A, Manca ML, Penno G, Gatti A, Anichini R, et al. Effectiveness of dapagliflozin versus comparators on renal endpoints in the real world: a multicentre retrospective study. Diabetes Obes Metab. 2019;21(2):252-60.

112. Heerspink HJ, Perkins BA, Fitchett DH, Husain M, Cherney DZ. Sodium glucose cotransporter 2 inhibitors in the treatment of diabetes mellitus: cardiovascular and kidney effects, potential mechanisms, and clinical applications. Circulation. 2016;134(10):752-72.

113. Hallow KM, Helmlinger G, Greasley PJ, McMurray JJV, Boulton DW. Why do SGLT2 inhibitors reduce heart failure hospitalization? A differential volume regulation hypothesis. Diabetes Obes Metab. 2018;20(3):479-87.

114. Schork A, Saynisch J, Vosseler A, Jaghutriz BA, Heyne N, Peter A, et al Effect of SGLT2 inhibitors on body composition, fluid status and reninangiotensin-aldosterone system in type 2 diabetes: a prospective study using bioimpedance spectroscopy. Cardiovascu Diabetol. 2019;18(1):46.

115. Kawanami D, Matoba K, Takeda Y, Nagai Y, Akamine T, Yokota T, et al. SGLT2 inhibitors as a therapeutic option for diabetic nephropathy. Int J Mol Sci. 2017;18:5

116. Baker WL, Smyth LR, Riche DM, Bourret EM, Chamberlin KW, White WB. Effects of sodium-glucose co-transporter 2 inhibitors on blood pressure: a systematic review and meta-analysis. J Am Soc Hypertens. 2014;8(4):262-75.e9.

117. Sano M, Goto S. Possible mechanism of hematocrit elevation by sodium glucose cotransporter 2 inhibitors and associated beneficial renal and cardiovascular effects. Circulation. 2019;139(17):1985-7.

118. Tomita I, Kume S, Sugahara S, Osawa N, Yamahara K, Yasuda-Yamahara $M$, et al. SGLT2 inhibition mediates protection from diabetic kidney disease by promoting ketone body-induced mTORC1 inhibition. Cell Metab. 2020;32(3):404-19.e6.

119. Kalra S. Sodium Glucose Co-Transporter-2 (SGLT2) inhibitors: a review of their basic and clinical pharmacology. Diabetes Ther. 2014;5(2):355-66.

120. Cai X, Yang W, Gao X, Chen Y, Zhou L, Zhang S, et al. The Association between the dosage of SGLT2 inhibitor and weight reduction in type 2 diabetes patients: a meta-analysis. Obesity (Silver Spring, Md). 2018;26(1):70-80

121. Bolinder J, Ljunggren $\mathrm{O}$, Kullberg J, Johansson L, Wilding J, Langkilde $A M$, et al. Effects of dapagliflozin on body weight, total fat mass, and regional adipose tissue distribution in patients with type 2 diabetes mellitus with inadequate glycemic control on metformin. J Clin Endocrinol Metabol. 2012;97(3):1020-31.

122. Apovian CM, Bigornia S, Mott M, Meyers MR, Ulloor J, Gagua M, et al. Adipose macrophage infiltration is associated with insulin resistance and vascular endothelial dysfunction in obese subjects. Arterioscler Thromb Vasc Biol. 2008;28(9):1654-9.

123. Rosito GA, Massaro JM, Hoffmann U, Ruberg FL, Mahabadi AA, Vasan RS, et al. Pericardial fat, visceral abdominal fat, cardiovascular disease risk factors, and vascular calcification in a community-based sample: the Framingham Heart Study. Circulation. 2008;117(5):605-13.

124. Mulyadi L, Stevens C, Munro S, Lingard J, Bermingham M. Body fat distribution and total body fat as risk factors for microalbuminuria in the obese. Ann Nutr Metab. 2001;45(2):67-71.

125. Stein P, Berg JK, Morrow L, Polidori D, Artis E, Rusch S, et al. Canagliflozin, a sodium glucose co-transporter 2 inhibitor, reduces post-meal glucose excursion in patients with type 2 diabetes by a non-renal mechanism: results of a randomized trial. Metabolism. 2014;63(10):1296-303.

126. Scheen AJ. Pharmacokinetic and pharmacodynamic profile of empagliflozin, a sodium glucose co-transporter 2 inhibitor. Clin Pharmacokinet. 2014:53(3):213-25.

127. Ferrannini E, lervasi G, Colligiani D, Ndreu R, Nannipieri M. Metabolic impact of normal thyroid hormone levels: a prospective study. Diabetologia. 2016;59(Suppl 1):S227-8.

128. Mann JFE, Orsted DD, Brown-Frandsen K, Marso SP, Poulter NR, Rasmussen $\mathrm{S}$, et al. Liraglutide and renal outcomes in type 2 diabetes. N Engl J Med. 2017;377(9):839-48.

129. Gerstein HC, Colhoun HM, Dagenais GR, Diaz R, Lakshmanan M, Pais $P$, et al. Dulaglutide and cardiovascular outcomes in type 2 diabetes (REWIND): a double-blind, randomised placebo-controlled trial. Lancet. 2019a;394(10193):121-30.

130. Gerstein HC, Colhoun HM, Dagenais GR, Diaz R, Lakshmanan M, Pais P, et al. Dulaglutide and renal outcomes in type 2 diabetes: an exploratory analysis of the REWIND randomised, placebo-controlled trial. Lancet. 2019b;394(10193):131-8.

131. Tuttle KR, Lakshmanan MC, Rayner B, Busch RS, Zimmermann AG, Woodward DB, et al. Dulaglutide versus insulin glargine in patients with type 2 diabetes and moderate-to-severe chronic kidney disease (AWARD-7): a multicentre, open-label, randomised trial. Lancet Diabetes Endocrinol. 2018;6(8):605-17.

132. Zelniker TA, Wiviott SD, Raz I, Im K, Goodrich EL, Furtado RHM, et al. Comparison of the effects of glucagon-like peptide receptor agonists and sodium-glucose cotransporter 2 inhibitors for prevention of major adverse cardiovascular and renal outcomes in type 2 diabetes mellitus. Circulation. 2019;139(17):2022-31.

133. Scheen AJ. An update on the safety of SGLT2 inhibitors. Expert Opin Drug Saf. 2019;18(4):295-311.

134. Baar MJB, Ruiten CC, Muskiet MHA, Bloemendaal L, Raalte DH. SGLT2 inhibitors in combination therapy: from mechanisms to clinical considerations in type 2 diabetes management. Diabetes Care. 2018;41(8):1543-56.

135. Cai Y, Liu X, Xu G. Combination therapy with SGLT2 inhibitors for diabetic kidney disease. Biomed Pharmacother. 2020;127:110192.

136. Thomas MC, Cherney DZI. The actions of SGLT2 inhibitors on metabolism, renal function and blood pressure. Diabetologia. 2018;61(10):2098-107.

137. Nadkarni GN, Ferrandino R, Chang A, Surapaneni A, Chauhan K, Poojary $P$, et al. Acute kidney injury in patients on SGLT2 inhibitors: a propensitymatched analysis. Diabetes Care. 2017;40(11):1479-85.

138. Rampersad C, Kraut E, Whitlock RH, Komenda P, Woo V, Rigatto C, et al. Acute kidney injury events in patients with type 2 diabetes using SGLT2 
inhibitors versus other glucose-lowering drugs: a retrospective cohort study. Am J Kidney Dis. 2020;76(4):471-9.e1.

139. Burke KR, Schumacher CA, Harpe SE. SGLT2 inhibitors: a systematic review of diabetic ketoacidosis and related risk factors in the primary literature. Pharmacotherapy. 2017;37(2):187-94.

140. Donnan JR, Grandy CA, Chibrikov E, Marra CA, Aubrey-Bassler K, Johnston $\mathrm{K}$, et al. Comparative safety of the sodium glucose co-transporter 2 (SGLT2) inhibitors: a systematic review and meta-analysis. BMJ Open. 2019;9(1):e022577.

141. Erondu N, Desai M, Ways K, Meininger G. Diabetic ketoacidosis and related events in the canagliflozin type 2 diabetes clinical program. Diabetes Care. 2015;38(9):1680-6.

142. Ueda P, Svanstrom H, Melbye M, Eliasson B, Svensson AM, Franzen S, et al. Sodium glucose cotransporter 2 inhibitors and risk of serious adverse events: nationwide register based cohort study. BMJ. 2018;363:k4365.

143. Yuan Z, DeFalco FJ, Ryan PB, Schuemie MJ, Stang PE, Berlin JA, et al. Risk of lower extremity amputations in people with type 2 diabetes mellitus treated with sodium-glucose co-transporter-2 inhibitors in the USA: A retrospective cohort study. Diabetes Obes Metab. 2018;20(3):582-9.

144. Ryan PB, Buse JB, Schuemie MJ, DeFalco F, Yuan Z, Stang PE, et al. Comparative effectiveness of canagliflozin, SGLT2 inhibitors and non-SGLT2 inhibitors on the risk of hospitalization for heart failure and amputation in patients with type 2 diabetes mellitus: A real-world meta-analysis of 4 observational databases (OBSERVE-4D). Diabetes Obes Metab. 2018;20(11):2585-97.

145. Li D, Yang JY, Wang T, Shen S, Tang H. Risks of diabetic foot syndrome and amputation associated with sodium glucose co-transporter 2 inhibitors: A Meta-analysis of Randomized Controlled Trials. Diabetes Metab. 2018:44(5):410-4.

146. Sinclair AJ, Bode B, Harris S, Vijapurkar U, Shaw W, Desai M, et al. Efficacy and safety of canagliflozin in individuals aged 75 and older with type 2 diabetes mellitus: a pooled analysis. J Am Geriatr Soc. 2016;64(3):543-52.

147. Yokote K, Terauchi Y, Nakamura I, Sugamori H. Real-world evidence for the safety of ipragliflozin in elderly Japanese patients with type
2 diabetes mellitus (STELLA-ELDER): final results of a post-marketing surveillance study. Expert Opin Pharmacother. 2016;17(15):1995-2003.

148. Maegawa H, Tobe K, Tabuchi H, Nakamura I, Uno S. Safety and efficacy of ipragliflozin in elderly versus non-elderly Japanese patients with type 2 diabetes mellitus: a subgroup analysis of the STELLA-LONG TERM study. Expert Opin Pharmacother. 2018;19(4):327-36.

149. Jordan J, Tank J. Complexity of impaired parasympathetic heart rate regulation in diabetes. Diabetes. 2014;63(6):1847-9.

150. Pugliese G. Updating the natural history of diabetic nephropathy. Acta Diabetol. 2014;51(6):905-15.

151. Barnett AH, Mithal A, Manassie J, Jones R, Rattunde $\mathrm{H}$, Woerle $\mathrm{HJ}$, et al. Efficacy and safety of empagliflozin added to existing antidiabetes treatment in patients with type 2 diabetes and chronic kidney disease: a randomised, double-blind, placebo-controlled trial. Lancet Diabetes Endo. 2014;2(5):369-84.

152. Kohan DE, Fioretto P, Tang W, List JF. Long-term study of patients with type 2 diabetes and moderate renal impairment shows that dapagliflozin reduces weight and blood pressure but does not improve glycemic control. Kidney Int. 2014;85(4):962-71.

153. Gilbert R, Weir M, Fioretto P, Davies M, Meininger G. Longer-term effect of canagliflozin treatment on eGFR in patients with type 2 diabetes mellitus. Presented at the International Diabetes Federation World Diabetes Congress 2015. 2015;Abstract: 0371-PD.

154. Leiter LA, Cefalu WT, de Bruin TW, Gause-Nilsson I, Sugg J, Parikh SJ. Dapagliflozin added to usual care in individuals with type 2 diabetes mellitus with preexisting cardiovascular disease: a 24-week, multicenter, randomized, double-blind, placebo-controlled study with a 28-week extension. J Am Geriatr Soc. 2014;62(7):1252-62.

155. Kambara T, Shibata R, Osanai H, Nakashima Y, Asano H, Sakai K, et al. Use of sodium-glucose cotransporter 2 inhibitors in older patients with type 2 diabetes mellitus. Geriatr Gerontol Int. 2018;18(1):108-14.

\section{Publisher's Note}

Springer Nature remains neutral with regard to jurisdictional claims in published maps and institutional affiliations.
Ready to submit your research? Choose BMC and benefit from:

- fast, convenient online submission

- thorough peer review by experienced researchers in your field

- rapid publication on acceptance

- support for research data, including large and complex data types

- gold Open Access which fosters wider collaboration and increased citations

- maximum visibility for your research: over 100M website views per year

At BMC, research is always in progress.

Learn more biomedcentral.com/submissions 